\title{
Theory and Practice of Quantitative Assessment of System Harmonicity: Case of Road Safety in Russia before and during the COVID-19 Epidemic
}

\author{
Artur I. Petrov ${ }^{1, *\left(\mathbb{D}, \text { Victor I. Kolesov }^{1} \text { and Daria A. Petrova }\right.}{ }^{2}$ \\ 1 Department of Road Transport Operation, The Institute of Transport, Industrial University of Tyumen, \\ 625027 Tyumen, Russia; vikolesov@yandex.ru \\ 2 The Institute of Natural Sciences and Mathematics, Ural Federal University named after the first President of \\ Russia B.N. Yeltsin, 620002 Ekaterinburg, Russia; daartpetrova@mail.ru \\ * Correspondence: ArtIgPetrov@yandex.ru; Tel.: +7-(912)-079-19-91
}

\section{check for} updates

Citation: Petrov, A.I.; Kolesov, V.I.; Petrova, D.A. Theory and Practice of Quantitative Assessment of System Harmonicity: Case of Road Safety in Russia before and during the COVID-19 Epidemic. Mathematics 2021, 9, 2812. https://doi.org/ $10.3390 /$ math 9212812

Academic Editors: Lina Novickyte, Jolanta Drozdz, Radosław Pastusiak and Michał Soliwoda

Received: 21 September 2021

Accepted: 24 October 2021

Published: 5 November 2021

Publisher's Note: MDPI stays neutral with regard to jurisdictional claims in published maps and institutional affiliations.

Copyright: (c) 2021 by the authors. Licensee MDPI, Basel, Switzerland. This article is an open access article distributed under the terms and conditions of the Creative Commons Attribution (CC BY) license (https:/ / creativecommons.org/licenses/by/ $4.0 /)$.

\begin{abstract}
People have had an interest in harmony issues for thousands of years; however, there is still no elaborated system of views on these questions. Ancient Greeks understood harmony as an agreement of opposites. A surge of interest in the study of the harmonic aspects of being occurred in the twentieth century due to the development of systems science, particularly regarding synergetic system effects. At the same time, there are still relatively few applications of synergetics because of the absence of an accurate methodology for the identification of system harmonicity. The aim of this research is to develop the methodology for the quantitative assessment of system harmonicity by considering a practical example: the quantitative assessment of the harmonicity of the road safety provision system (RSS) and its dynamics during the last 15 years (2006-2020). In addition, the impact of the COVID restrictions on population mobility in Russia in 2020, on the change in the harmonicity of the road safety provision system, is considered. During the research it was established that the quality factor $g$ of the Russian road safety provision system changed from $g_{2006}=1.9565$ to $g_{2020}=2.4646$, which promoted the decline of the relative entropy of the Russian road safety provision system from $H_{n}$ RSS 2006 $=0.8623$ to $H_{n}$ RSS 2020 $=0.7553$. The deep reason for that change was the modification of relation between "weights" or the significance of the contribution of different elements of the cause-and-effect chain in the formation of the factual level of the road accident rate in Russia in the last 15 years. The main conclusion of this research is that the harmonicity of the Russian road safety provision system, assessed by the normalized functional general utility $G U_{n}$, has been increased, and it has already exceeded the level of harmonious reference systems $G U_{n}=0.618$. In fact, the normalized functional general utility $G U_{n}$ of the Russian road safety provision system increased from $G U_{n} R S S 2006=0.615$ to GUn RSS $2020=0.652$ (by 6.0\%), from 2006 to 2020. Simultaneously, the share of the normalized used resource $X_{n}$ declined, allowing a conclusion to be drawn about a significant improvement in the balance "efficiency-quality" of the Russian road safety provision system. The COVID lockdown played a positive role in this process. Harmonicity of the Russian road safety provision system, assessed by the normalized general utility $G U_{n}$ RSS, increased by $0.46 \%$ from 2019 to 2020 .
\end{abstract}

Keywords: system structural harmonicity; synergetics; orderliness; entropy; generalized golden ratio (GGR); quantitative assessment; road safety; COVID-19 epidemic; Russia

\section{Introduction}

The year 2020 will go down in history as a very unusual year. The Great Reset is a relevant slogan, the authors of which in the context of the events of 2020 and subsequent years are K. Schwab and T. Malleret [1]. Widespread lockdowns forced the transfer of activity from off-line to on-line. The forced decline in activity has changed people's lifestyles everywhere. Naturally, this caused a decrease in the transport mobility of people. 
To a greater extent, this concerned citizens in the largest cities of the world whose transport traffic, according to the Tom Tom Traffic Index [2], decreased by $20-80 \%$ during the active lockdown phase (April-May 2020) [3]. Rural residents were also forced to reduce transport activity, although to a lesser extent than urban residents [4]. This could not but affect various aspects of the functioning of the transport sector of the economy. Primarily, this concerns road safety.

Data analysis of the Road Safety Annual Report 2020 [5] indicates two important facts. In countries with a hard lockdown in the spring of 2020, the number of deaths in road accidents significantly decreased; when comparing "April 2020 to April 2019", road traffic mortality reduced by $30-80 \%$. Conversely, in those few countries where lockdown was not introduced, the death rate in road accidents increased; in Sweden and the Netherlands, the countries that are long-standing world leaders in road safety, the number of people killed in road accidents in April 2020 increased by 6\% compared to April 2019. Of course, all this could not go unnoticed by the regional authorities, or by the global level of government.

One of the most important decisions of the 74th session (18.08.2020) of the United Nations (UN) General Assembly was resolution A/RES/74/299, "Improving global road safety" [6]. This document highlights the importance of the work already conducted in this area over the past decade. It also formulates the need to achieve a new goal by 2030, which is to reduce the number of deaths on roads by $50 \%$. It should be assumed that this ambitious goal was formulated at the time when the first results of the assessment of the COVID lockdown's impact on road traffic accidents had already been received, and the connection between the restriction in transport mobility and the number of fatalities in road accidents was comprehended. Perhaps these statistics largely served as the basis for cautious optimism in promoting the concept of Mobility-as-a-Service (MaaS), which is the ideological basis for abandoning personal transport in favor of a transportation service provider. Expectation of the upcoming mass rejection of the individual car is perhaps the main reason for optimism about potential trends in road safety. In some countries, targets have been announced for a multiple reduction in the number of people killed in road accidents over the next decade [7,8]. An example of such goal-setting is the Russian Federation [9], where the task is to reach a level of human risk of four deaths in road accidents per hundred thousand people by 2024, and a level of zero mortality in road accidents by 2030 [10]. For reference, in 2020, the level of human risk in Russia was equal to 10.80 people killed in road accidents per hundred thousand people [11]. Meanwhile, no assessment of the real possibility of achieving this goal was carried out.

How possible is the success of the practical implementation of this target setting? How did the COVID restrictions affect the effectiveness, usefulness and harmony of state road safety systems? These are the most important issues and are discussed by the authors from the standpoint of the theory of system harmony, when comparing the situation in the field of assessing the organization of the state system for ensuring road safety in the Russian Federation during characteristic periods (between 2006 and 2020, and comparing the situation of 2019, a conditionally normal year, to 2020, the lockdown year).

\section{Related Works}

\subsection{Synergetics, Orderliness and System Harmonicity}

The subject of synergetics can be defined as the study of the process of system selforganization. Social synergetics studies the patterns of self-organization of society, i.e., the relationship between social order and social chaos (their mutual transition into one another and their synthesis). R. Benedict [12] is the author of the "synergy" concept and initially the authors specializing in the interaction between the individual and society were engaged in the problems of synergy [13]. Today, synergetics is mainly a tool of cognition in the social sciences [14-17].

However, it is generally recognized that the main ideas of synergetics were laid down in the works of scientists of the natural science profile: I. Prigogine, I. Stengers, and G. Nicolis [18-21]. 
Nevertheless, H. Haken can be considered the founder of synergetics [22-24]. He defined synergetics as the science of self-organization, the theory of "the joint action of many subsystems, that in result arises a structure and corresponding functioning at the macroscopic level" [23].

This is mentioned in analytical works $[25,26]$.

Today, synergetics is recognized as a scientific direction all over the world. In Russia, the ideas of synergetics were actively promoted and developed by scientists of the scientific group of S. P. Kurdyumov [27,28].

Synergetics made a revolution by creating a new image of the world that continuously evolves according to nonlinear laws.

The basic concepts of synergetics are "order" and "chaos". The concept of "order" is usually used when describing a system of stable, repetitive in space and time relationships between elements of any nature. Conversely, the concept of "chaos" is usually used to describe a set of elements between which there are no stable repeating relationships. Dissipative systems, which include any socio-technical systems, can exist only in conditions of a constant exchange of matter, energy and information with the external environment [18]. The existence of a dissipative system is based on a constant synthesis of order and chaos. It has two aspects. Firstly, its system order exists only due to the chaos injected into the environment. Secondly, the system acquires the ability to adequately respond to chaotic influences of the external environment and thereby maintain its stability due to its system order. This remark primarily concerns structural stability preservation. It is possible if the system has a high level of orderliness.

Orderliness is the property of a system to preserve the structural composition, i.e., to restrict the freedom of change of both the system's element set and the connections between the elements. Usually, in a society, orderliness is a consequence of the practical implementation of functioning of a set of attitudes, laws and prohibitions that structure the system and organize its functioning within a clear system of rules. System orderliness is connected with its harmony.

The functioning of complex systems, which include all forms of transportation systems, is based on two global laws: the first law of dialectics and the law of the generalized golden ratio (GGR).

The first law of dialectics is the law of unity and the struggle of the opposites. Its essence can be expressed in the following form:

$$
\text { Positive }+ \text { negative }=\text { universe }
$$

which, after normalization, is reduced to the form (1):

$$
a+b=1
$$

where

$a$-dominant;

$b$-subdominant.

In the structural identification of the concept of system sustainability, we will use the first law of dialectics in form (1), taking an increase in utility as a positive and a loss of sustainability as a negative:

$$
\text { Positive }(P)+\text { negative }(N)=\text { universe }(U) \text {. }
$$

The law of the generalized golden ratio (S-ratio) was identified by E. M. Soroko [29] and it has the following analytical form (2):

$$
\left(\frac{1}{a}\right)^{s}=\frac{a}{b}=\frac{a}{1-a}
$$


where $s$-so-called multiplicity indicator.

In complex systems management, the law of the generalized golden ratio was the predecessor of modern F-technologies. In general, both laws are tools for building system functionality and structure close to the standard. The purpose of reference transport systems functionality is to form the general utility $(G U)$ when consuming the provided resource. Thus, it is necessary to identify the general utility model. To do this, it is necessary to identify it structurally and parametrically.

\subsection{Road Safety Is a System Property. Road Safety as a Result of Functioning of a Specialized System for Preventing Conflict Road Traffic Situations}

A variety of authors have considered road safety from a system perspective. In the period of 1950-1970 many authors brought the consideration of road safety to the system level [30-35]. In many ways, this was promoted by the general theoretical work of L. Von Bertalanffy [36]. Road safety specialists relied on this work and considered the problems of road traffic accidents not as a set of special cases, but as a demonstration of a system peculiarity.

The result of this work was the concept of "Vision Zero", as Sweden's Traffic Safety Policy, declared in 1997 [37]. Two and a half decades of implementation of this concept, at first in the Scandinavian countries, and then, albeit partially, in many others, have shown the high efficiency of using the system approach in road safety provision.

P. Larsson et al. [38] believe that "the so-called zero-tolerance position, or Vision Zero approach, to road safety is built around two axioms; the system must be adapted to the psychological and physical conditions and limitations of the human being and the responsibility for road safety must be shared between the road-users and the designers and professional operators of the system". This is an important thesis that requires road traffic organizers to have a professional understanding of the cause-and-effect relationships of the process of forming of road traffic accidents and active actions to minimize the negative consequences in the chain of events.

A. Szymanek [39] has a similar opinion: "The road safety management methodology should be based on a system approach. This means that the road transport must be formalized as a complex system (CS), and then safety can be interpreted as an emergent feature of such a system. Road accidents should be interpreted as "organizational accidents".

B. P. Hughes et al. systematize various approaches of road safety provision in [40]. The analysis of 2620 literary sources conducted by the authors allowed them to summarize the experience in the road safety sphere in various countries in the form of 121 different types of models. This diversity of models for road safety provision is explained by a wide range of different targets and restrictions. This is an illustrative example of a wide variety of approaches, among which there may be the most unexpected ones.

\subsection{General Trends of Road Safety Changes}

At various times, scientists from all over the world were interested in the issues of road safety provision [41-51]. The analysis of the content of most of these studies allows us to conclude about the positive global changes in trends in road safety. The statistics of such organizations as the World Health Organization [52], IRTAD Group and permanent working group on road safety of the International Transport Forum [53] confirm this fact.

R. Elvik and R. Goel [54] state that "recent studies find a stronger tendency towards safety-in-numbers than older studies". This remark applies to the majority of the economically and socially developed countries of the world [55], but not to all of them. The economically and socially underdeveloped countries of Africa and Southeast Asia are characterized not only by a relatively high level of road traffic accidents, but also by trends in its increase. This spatial heterogeneity of road safety trends on a global scale is explained by the fact that different paradigms of road safety provision are currently relevant in different countries [56]. This means that some developing countries now have a level of road safety provision at approximately the same level as it was 30-70 years ago, from 1950 to 1990 in currently leading countries in the field of road safety. 
While we consider the general trends in road safety, we should understand that the attention of states to the issues of reducing road traffic accidents and deaths in road accidents is largely related to the socio-economic aspects of life, particularly to one of the most important-the damage caused by the decrease in the quality of citizens' human potential. Thus, it is shown in [57] that the total costs of road crashes in 31 European

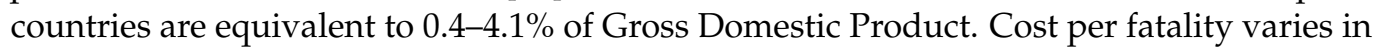
different European countries in the range from $€ 0.7$ million to $€ 3.0$ million.

According to L. J. Blincoe et al. [58], the economic cost of US motor vehicle crashes that occurred in 2010 totaled $\$ 242$ billion. This is equivalent to $1.6 \%$ of the US Gross Domestic Product.

These facts indicate that the problem of road traffic accident rate is highly significant both from the social and economic sides for most countries of the world. This is the reason for a serious increase in attention to the issue of road safety that has been paid in recent years in almost all countries of the world. As a result, in the vast majority of countries of the world, the general trends in changes in road safety are quite encouraging.

\subsection{Factors Influencing Road Safety}

\subsubsection{The Road User Factor}

Long-term experience [59-87] allowed us to establish that the contribution of the human factor to the road traffic accident rate is at least $90 \%$. That is why autonomous car driving technologies have been rapidly developing in recent years [59-62], and the possibility of removing a person from the process of driving a vehicle has been actively studied [63]. However, in recent decades, there has been a huge improvement in the road transport infrastructure in various countries [64-66]. Many organizational and technical solutions are devoted to the minimization of the possibility of direct contact between a pedestrian and a driver $[67,68]$. Another direction of road safety improvement involves administrative actions, such as reducing the speed of vehicles in cities [69] and monitoring drivers' behavior $[70,71]$. In this regard, it is important to analyze the main approaches to assessing the driving style of drivers.

In 2004, O. Taubman-Ben-Ari et al. [72] published an article that proposed to classify the style of driving according to danger to others. The authors proposed to select eight typical driving styles. In the same article, the results of statistical research were presented, which aimed to identify a factor relationship between belonging to a particular driving style and the characteristic features of Israeli drivers who were representatives of different styles.

As indicated in the article by $\mathrm{O}$. Taubman-Ben-Ari et al., the ideas of classifying drivers by driving styles are based on earlier works [73,74].

A little later, the method by O. Taubman-Ben-Ari et al. was modernized by Spanish [75] and Romanian authors [76].

In 2019, similar studies were conducted by Bulgarian researchers Z. Totkova and R. Racheva, who modernized the method and presented their version of factor analyses of the multidimensional driving style inventory (MDSI-BG) in [77].

The above studies were highly useful for understanding the psycho-physiological differences between different drivers and their different contributions to the formation of the actual road safety level.

A lot of works are also devoted to the issues of the impact of road users' sex and age on the road traffic accident rate [78-80]. Almost all of these studies indicate a greater tendency to unjustified risk, which is a risk factor for accidents, in young inexperienced male drivers with a low level of education and internal culture [81-83]. Conversely, women are more attentive and careful on the road than men [84]. It is also established that more educated professionals with a reliable workplace perform significantly less hazardous driving techniques than uneducated unemployed people [85]. There is also evidence of an inverse positive relationship between road traffic accidents and the general employment of people [86,87]. 


\subsubsection{The Factor of Road Transport Infrastructure and Traffic Control Systems}

Many works are devoted to the issues of the connection between road transport accidents and the quality of road transport infrastructure $[88,89]$. Numerous studies have been devoted to this topic in the context of the Third Paradigm of road safety [56]. Today, most developed countries make the highest requirements to the quality of the roadway, as well as to the engineering equipment of highways and the road network of cities. Nevertheless, even today, research on the further improvement of engineering systems for road safety provision is being conducted. One of the most important areas of such research is the identification of potentially dangerous locations for road users in the city. On the basis of these locations, new engineering solutions contributing to greater security will be developed and implemented [90-98].

The analysis of these works shows that creation of a high-quality road network is an expensive and resource-intensive task. Its solution has many limitations. In this regard, in the current situation, one of the most efficient ways to increase traffic safety is to identify dangerous locations, notify drivers about their existence and increase control of driving behavior on these sections of the road network.

\subsubsection{The Factors of the Technical Level and Quality of the Vehicle}

Researchers have been paying attention to car safety issues for more than 100 years. In this direction, especially effective research was carried out in the period from 1960 to 2010. During this time, cars have become much safer and much less demanding on the driver's qualifications. The level of active, passive and post-accident safety of individual cars has significantly increased. Duplication of safety systems, decrease in the probability of an accident and decline of the injury risks in an accident are the results of many years of work of designers, production technologists and researchers in the field of road safety. According to $[99,100]$, the poor technical condition of vehicles and related technical failures were the cause of only $1-1.5 \%$ of accidents in EU countries (but $5-7 \%$ of accidents were caused by a combination of the technical failure of the car and incompetent actions of the driver in this critical situation).

\subsubsection{The Factors of the External Environment That Negatively Affect Traffic Conditions}

Many studies have been devoted to the influence of negative manifestations of the external environment on road safety [101-103]. In general, summarizing the results of these studies, it can be concluded that in adverse weather and weather-related road conditions, the accident rate increases significantly. That is why in countries with a high level of socio-economic development, active road signs and information boards are used on federal highways and in cities to regulate traffic flow modes taking into account environmental conditions [104-106]. This significantly reduces the risk of accidents. Unfortunately, such advanced technologies are used in a small number of countries. In most countries, the driver chooses the speed mode independently, without external informational support [107].

\subsection{COVID Lockdown and Its Influence on Road Safety}

In 2020 and 2021, a lot of works were published on the study of the impact of the COVID lockdown on changing people's transport behavior and, as a result, on changing the characteristics of road traffic accidents in various countries of the world [108-113]. Studies by $[108,109]$ are devoted to changes in the patterns of using public and individual transport in the conditions of COVID-19. It was established that in 2020, people were afraid of the risks of infection and significantly reduced the frequency of using transport services. The same conclusion was made with regard to the use of individual cars and the mobility of citizens in general.

A study by Indian authors [110] shows that during the spring lockdown period (from 24.03.2020 to 31.06.2020), in comparison with the same period of 2019, India recorded a 
decrease in the number of road accidents by $68 \%$ and in the number of the dead and injured in road accidents by $62 \%$ and $72 \%$, respectively.

According to the report "Impact of COVID-19 on Road Crashes in Australia" [111]: "fatalities among drivers $(-5 \%)$, passengers $(-11 \%)$, pedestrians $(-20 \%)$ and motorcycle riders $(-12 \%)$ decreased during the COVID lockdown, but pedal cyclist fatalities across Australia increased by $29 \% "$.

In [112], the Greek authors, on the basis of studies conducted in Greece and Saudi Arabia in March-April 2020, showed that "reduced traffic volumes due to lockdown, led to a slight increase in speeds by $6-11 \%$, but more importantly to more frequent harsh acceleration and harsh braking events (up to $12 \%$ increase) as well mobile phone use (up to $42 \%$ increase) during March and April 2020, which were the months where COVID-19 spread was at its peak. On the bright side, accidents in Greece were reduced by $41 \%$ during the first month of COVID-19-induced measures and driving in the early morning hours (00:00-05:00), which are considered dangerous, dropped by up to $81 \% "$.

Summarizing the results of the above studies, it can be concluded that road safety during the lockdown restrictions in various countries of the world was largely determined by the peculiarities of the manifestation of transport activity. Based on these observations, L. Budd and S. Ison made conclusions about the need to develop new concepts and strategies of transport policy [113]. The main idea of these authors is that it is necessary to increase awareness of the choice of the method of mobility from the perspective of health safety in the future.

\section{Theoretical Solution to the Problem of Assessing Systemic Harmonicity}

\subsection{Identification of the Concept of "Reference Systems"}

Reference systems are open, interacting with the external environment, multicomponent systems with a number of specific features such as:

- they work in the mode of generalized golden ration (GGR) [29];

- their normalized utility function is described by the Equation (3):

$$
G U_{n}=1-(1-x)^{g}
$$

where

GU - the normalized general utility;

$x$-the share of consumed resource;

$\mathrm{g}=1+\mathrm{s}-\mathrm{Q}$-factor-system quality indicator;

$\mathrm{s}$ - the multiplicity parameter, independent of $x$.

- they have real (independent of argument $\mathrm{x}$ ) values of the quality factor $\mathrm{g}$.

\subsection{Functionality of Reference System}

The essence of the functionality of reference systems of urban mobility management is to deliver the general utility of $G U$ in the consumption of the provided resource. The macro-model of the normalized general utility $G U_{n}$ is represented as (3). A significant advantage of this macro-model type is that it has fractal properties. Suppose that the argument $\mathrm{x}$ is an analogous function of the new parameter $T_{n}$, i.e.,

$$
x=1-\left(1-T_{n}\right)^{s}
$$

then normalized general utility $G U_{n}$ can be represented as:

$$
\operatorname{GU}_{n}\left(T_{n}\right)=1-(1-x)^{g}=1-\left\{1-\left[1-\left(1-T_{n}\right)^{s}\right]\right\}^{g}=1-\left[\left(1-T_{n}\right)^{s}\right]^{g}=1-\left(1-T_{n}\right)^{q}
$$

Obviously, the new result (3) is again a fractal that has normalized time $T_{n}=t / T$ as an argument (here $T$ is a lifecycle time). The creation of the new model (3) allows us to proceed to the analysis of its dynamic characteristics. 


\subsection{Analysis of the Dynamic Characteristics of Reference Systems' Functionality}

For the development of an algorithmic provision for road safety management systems it is necessary to have models of the basic dynamic characteristics of the information process. Article [114] is devoted to the topic of the development of such provision.

The functional scheme of the process (Figure 1) identifies dynamic models of the following process characteristics:

- $\quad$ speed of the change of process utility SGU (speed of general utility):

$$
\operatorname{SGU}\left(T_{n}\right)=d G U\left(T_{n}\right) / d T_{n}
$$

- $\quad$ process utility GU (general utility):

$$
G U\left(T_{n}\right)=\int_{0}^{T_{n}} S G U_{p}\left(T_{n}\right) \cdot d T_{n}
$$

- $\quad$ vital power (performance) of process VP (vital power):

$$
\operatorname{VP}\left(T_{n}\right)=G U\left(T_{n}\right) \cdot S G U_{p}\left(T_{n}\right)
$$

- $\quad$ reserve of process vital power $S$ (stamina):

$$
S\left(T_{n}\right)=\int_{0}^{T_{n}} V P\left(T_{n}\right) \cdot d T_{n}
$$

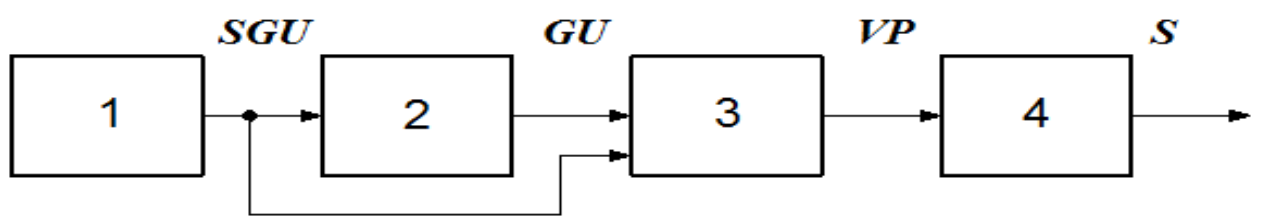

Figure 1. Functional scheme of the road safety management process (system).

\begin{tabular}{|c|c|c|}
\hline Model & Determination Algorithm & \\
\hline Normalized speed of the change of process utility $S G U_{n}$ & $\begin{array}{c}S G U_{n}\left(T_{n}\right)=S G U_{p}\left(T_{n}\right) / S G U_{p \max }=\left(1-T_{n}\right)^{q-1} \\
\text { wheresGU }\end{array}$ & $(10)$ \\
\hline Normalized process general utility $G U_{n}$ & $G U_{n}\left(T_{n}\right)=1-\left(1-T_{n}\right)^{q}$ & $(11)$ \\
\hline Normalized vital power (performance) of process $V P_{n}$ & $V P_{n}\left(T_{n}\right)=\frac{V P\left(T_{n}\right)}{V P_{\max }}=\frac{q \cdot Z^{q-1} \cdot\left(1-Z^{q}\right)}{\left(\frac{q-1}{2 q-1}\right)^{\frac{q-1}{q}} \cdot \frac{q^{2}}{2 q-1}}$ & $(12)$ \\
\hline Normalized reserve of process vital power $S_{n}$ & $S_{n}\left(T_{n}\right)=\frac{S\left(T_{n}\right)}{S_{\max }}=\left[G U\left(T_{n}\right)\right]^{2}$ & $(13)$ \\
\hline
\end{tabular}

Let us introduce the normalization of the above mentioned dynamic characteristics (Table 1).

Table 1. Dynamic models of system characteristics.

Let us explain the models (10-13).

From the perspective of the quality of system changes management process it is preferable to have not only a high level of technology perfection (determined by the level of general utility $G U\left(T_{n}\right)$ ), but also a high growth rate $S G U_{p}\left(T_{n}\right)=d G U\left(T_{n}\right) / d T_{n}$. 
In this regard, we can take as a criterion of effectiveness (vital power) of the system management process the next value (14):

$$
V P\left(T_{n}\right)=G U\left(T_{n}\right) \cdot S G U_{p}\left(T_{n}\right)=q \cdot Z^{q-1} \cdot\left(1-Z^{q}\right)
$$

where $Z=\left(1-T_{n}\right)$.

From the engineering point of view the question about the extremum of vital power $V P\left(T_{n}\right)$ is interesting. Its maximum is reached under the condition (15):

$$
d V P\left(T_{n}\right) / d T_{n}=0
$$

The solution of the Equation (15) is (16):

$$
\mathrm{Z}_{\text {opt }}=\left(\frac{q-1}{2 q-1}\right)^{\frac{1}{q}}
$$

The maximum possible value of the process vital power $V P$ is reached under the condition (17):

$$
V P_{\max }=\left(\frac{q-1}{2 q-1}\right)^{\frac{q-1}{q}} \cdot \frac{q^{2}}{2 q-1}
$$

The normalized value of the process vital power $V P_{n}$ is determined by the algorithm (18):

$$
V P_{n}\left(T_{n}\right)=\frac{V P\left(T_{n}\right)}{V P_{\max }}=\frac{q \cdot Z^{q-1} \cdot\left(1-Z^{q}\right)}{\left(\frac{q-1}{2 q-1}\right)^{\frac{q-1}{q}} \cdot \frac{q^{2}}{2 q-1}}
$$

In Table 1 model (18) is denoted as (12).

Argument $T_{n}$ opt , corresponding to the maximum of effectiveness of the controlled process, is determined by (19):

$$
T_{\text {nopt }}=1-Z_{\text {opt }}=1-\left(\frac{q-1}{2 q-1}\right)^{\frac{1}{q}}
$$

The reserve of vital power of population mobility management process can be interpreted as cumulative sum of vital powers on the interval $T_{n}(20)$ :

$$
S\left(T_{n}\right)=\int_{0}^{T_{n}} V P\left(T_{n}\right) \cdot d T_{n}=\int_{0}^{T_{n}} G U \cdot d G U / d T_{n} \cdot d T=\int_{0}^{G U\left(T_{n}\right)} G U \cdot d G U=\frac{G U^{2}\left(T_{n}\right)}{2}
$$

The level of reserve of vital powers at the end of the lifecycle is (21):

$$
S_{\max }=\int_{0}^{1} V P\left(T_{v}\right) \cdot d t_{v}=\int_{0}^{1} G U \cdot d G U / d T_{n} \cdot d T=\int_{0}^{1} G U \cdot d G U=\frac{1}{2}
$$

Introduction of the normalization generates model (22):

$$
S_{n}\left(T_{n}\right)=\frac{S\left(T_{n}\right)}{S_{\max }}=\left[G U\left(T_{n}\right)\right]^{2}
$$

In Table 1 model (22) is denoted as (13).

\subsection{The Research of the Structural Features of Utility Function of System Management}

When analyzing the structure of general utility $G U$ in multicomponent systems we should take into account two main points: 
- the general utility GU of a complex system is an additive composition of individual functions of utility of system components;

- the general utility GU of urban mobility management is a consequence of interaction between chaotic state and orderliness of processes in this sphere.

When assessing the general utility $G U$ of a complex system we need to identify the contribution of each component to the total success. A Pareto chart $(P C)$ is a traditional tool for this type of analysis. It represents a cumulative function of the contribution of individual components into a total balance. As a rule, $P C$ is approximated by a function (23):

$$
P C=1-(1-x)^{g}
$$

where

$x$-normalized rank; $x=r_{i} / r_{\max }$;

$r_{i}$ and $r_{\max }$ - correspondingly current and maximal ranks;

$g=1+s-Q$-factor-system quality indicator;

$g$ and $s$-indicators.

Since $P C$ is the increasing sum of "weights" of system components, it allows us to analytically deduce "weight" coefficients as (24):

$$
\omega_{i}=P C_{i}-P C_{i-1}=\left(1-\frac{i-1}{n}\right)^{g}-\left(1-\frac{i}{n}\right)^{g}
$$

Essentially, the normalized Pareto chart also represents the function of general utility $G U$, where $x$ is a share of the consumed resource. A comparison of models (3) and (23) indicates their functional equivalence $P C(x)=G U(x)$.

Found "weight" coefficients $\omega_{i}$ are used to solve two significant problems:

- $\quad$ the estimation of relative structural entropy $H_{n}[29,115,116]$, characterizing the level of orderliness (and structural perfection) of a process or system (25):

$$
H_{n}=\left[-\sum_{i=1}^{n} \omega_{i} \cdot \ln \left(\omega_{i}\right)\right] / \ln (n)
$$

- $\quad$ representation of utility function $G U(x)$ in additive form (26):

$$
G U(x)=\sum_{i=1}^{n} G U_{i}(x)=\sum_{i=1}^{n} \omega_{i} \cdot\left[1-(1-x)^{g}\right]
$$

where

$G U_{i}(x)$-an individual utility function (the share of contribution of $i$-component to the final system result).

Let us examine the second approach in detail.

Its specifics are generated by the wide usage in modern computer-aided manufacturing systems of F-technologies (F-Fibonacci). F-technologies exploit Fibonacci algorithms to build highly efficient and harmonic technical, socio-economic and organizational systems. One of the leading experts in this sphere is E. M. Soroko $[29,115,116]$. He found that in the majority of situations the principle of generalized golden ratio (GGR) works when the proportion between parts of the unit interval $f_{r}$ and $f_{s}$ (meeting the condition of normalization $f_{r}+f_{s}=1$ ) is right (27):

$$
\left(1 / f_{r}\right)^{s}=\left(f_{r} / f_{s}\right)=f_{r} /\left(1-f_{r}\right)
$$

From (27) it follows, that (28):

$$
f_{r}^{g}+f_{r}-1=0
$$


where

$f_{r}$-dominant;

$1-f_{r}=f_{s}$-subdominant;

$g=1+s-Q$-factor-system quality indicator

$g$ and $s$-indicators.

The generalized golden ratio regime (GGR regime) directly relates to the functionality of reference management systems, presented as a macromodel of normalized general utility $G U_{n}$ (3). Its graphic representation as Pareto chart $P C(x)$ (taking into account equivalency $P C(x)=G U(x))$ is shown in Figure 2.

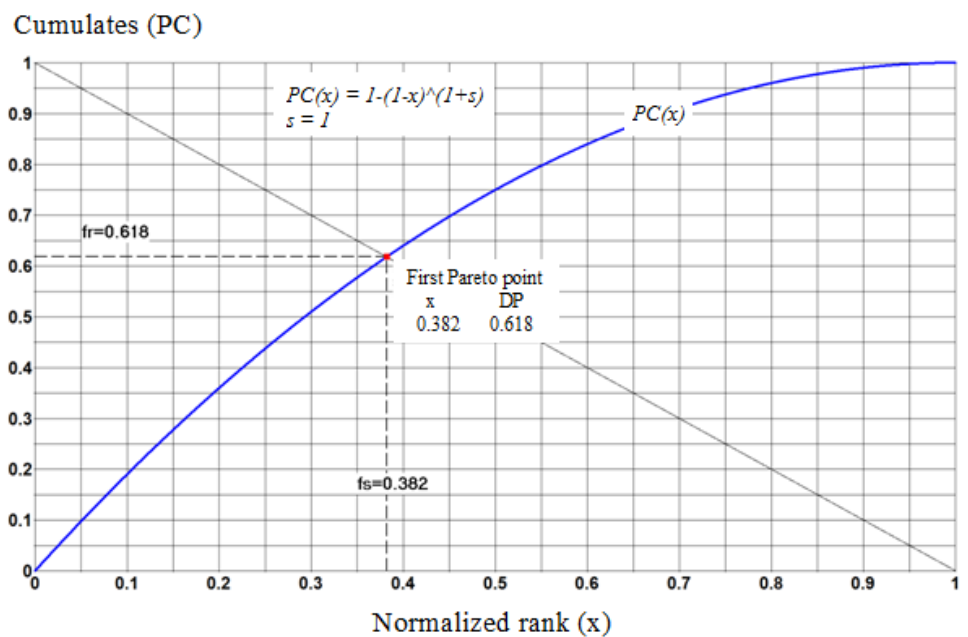

Figure 2. Macromodel of normalized general utility $G U_{n}$ in the form of Pareto chart.

The GGR regime is presented in the figure as a diagonal $y=(1-x)$, where every point meets the condition $y+x=1$. The point of intersection of the diagonal and Pareto chart (with coordinates $f_{s}$ and $f_{r}$ ) is called the first Pareto point. We want to highlight its properties. Firstly, it complies with the GGR principle. Secondly, it is related to indicator $g$ (system quality factor) by the correlation (29):

$$
g=1+s=\frac{\ln \left(1-f_{r}\right)}{\ln \left(1-f_{s}\right)}
$$

Thirdly, it is predetermined by proportion «order/chaos» in the management system. The meaning of the dominant $f_{r}$ and $f_{s}$ the subdominant is fundamentally important. The approach, evaluating levels of orderliness and chaos in an informational metric, where the maximal relative entropy of combination is taken as a unit, is foundational. The use of such approach allowed the creation of the theory of systems harmony [29]. However, at the same time, there is some non-transparency of the harmony concept in terms of engineering of efficient systems of urban mobility management. Let us consider the methodology of the optimal synthesis of harmonic systems in the examined domain sphere.

If we assume that the target management function is the retention of a process at the first Pareto point, then we need to prove that it provides an optimum in terms of predetermined parameter; in our case by default it is harmony. However, the harmonicity concept is not clearly formalized yet, and the question of an acceptable metric remains open. It is obvious that the total process utility in the first Pareto point is higher, the larger value of parameter $g$. However, the choice of the optimal value of the indicator $g$ is not simple. With a decline in the value of indicator $g$, system losses should increase due to the poor quality of the system. With the growth of the indicator $g$ the system efficiency should increase and, as a consequence, the additional expenses on the implementation of a system's functioning would grow. This problem belongs to the optimization category, 
where we need to establish which conditions provide minimal total expenses $Z$ and what is the value of the reached extremum $Z_{\text {min }}$.

The solution to this problem is given in the work [117]. A short explanation is given below.

In the paper it is supposed that the total expenses $Z$ are caused by the simultaneous effect of two mechanisms:

- on the one hand, a low value of the indicator g indicates a low system efficiency and, as a consequence, it is related to unwanted losses $Z_{1}$;

- $\quad$ on the other hand, a growth of the value $g$ is impossible withoud additional expenses $Z_{2}$.

Equation (28), written in the form $1-f=f^{g}$ ( $f$ - is a dominant of GGR regime), reaches a compromise. The left part characterizes the negative of decline of the $f$ dominant, while the right part characterizes the positive, provided by its growth.

The negative $(1-f)$ leads to proportianal losses $Z_{1}=C_{1} \cdot(1-f)$ (where $C_{1}-$ cost), when the positive $f^{g}$ demands proportional expenses $Z_{2}=C_{2} \cdot f^{g}$.

Therefore total expenses are (28):

$$
Z=Z_{1}+Z_{2}=C_{1} \cdot(1-f)+C_{2} \cdot f^{g}
$$

It is important that the price $C_{1}$ can have a broad meaning. Price $C_{1}$ can be understood as money, energy, information, time and other resource types. The essence of article [117] consists in the fact that the harmonic regime is the regime of provision of the minimal total resource expenses in the first Pareto point.

It is established in [117] that the level of total expenses $Z$ is (31):

$$
Z=Z_{\max } \cdot\left(1-f+m \cdot f^{g}\right)
$$

where $m=\frac{1}{g \cdot f_{r}^{g-1}}$.

The normalized value of expenses equals to $Z_{n}$ (32):

$$
Z_{n}=Z / Z_{\max }=\left(1-f+m \cdot f^{g}\right)
$$

The minimum of expenses is reached under the condition $d Z_{n} / d f_{r}=0$. Value of extremum $Z_{n}$ min equals to (33):

$$
Z_{n \min }=1-f_{r} \cdot(1-1 / g)
$$

and the level of minimal total expenses equals to (34):

$$
Z_{\min }=Z_{\max } \cdot\left[1-f_{r} \cdot(1-1 / g)\right]
$$

\subsection{Establishment of the Relation between Functionality and Structure}

Associating the system functionality with the function of general utility $G U$, it was detected that the key characteristic of $G U$ is the indicator $g$, which determines the level of success (the positive) in the consumption of the available resource and the structure of "weight" coefficients (relation (23)). However, the "weight" structure in turn predetermines the level of relative entropy $H_{n}$ (25). Therefore, the relation between $g$ and $H_{n}$ is quite expected (Figure 3). 


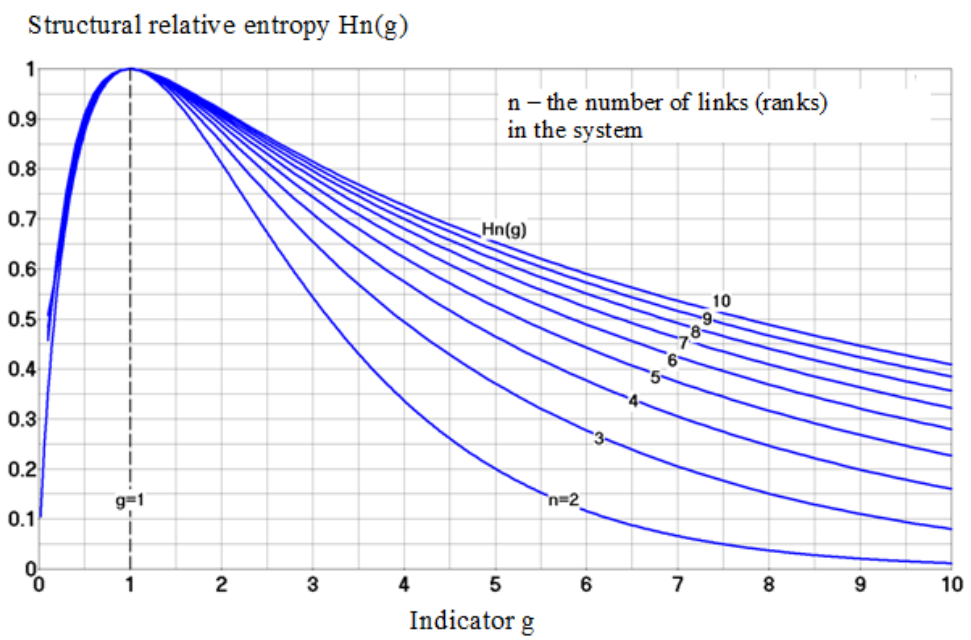

Figure 3. Model $H_{n}=f(g)$.

\subsection{Identification of Model of Evaluation of Reference Systems' Efficiency}

The successful solution of management problems is based on competent goal-setting, the quantitative measure of which is an efficiency. Formally, efficiency is a relation of performance to the resource expenses on results' achievement.

Let us consider the interpretation of the concept of "performance".

Traditionally, success is associated with the dominant $f_{r}$; the higher the dominant, the more positive the result. Since $f_{r}$ is a measure of the total utility, as a consequence, it can be a characteristic of the performance of the examined process. Model $G U=f(g)$ is a useful tool for success evaluation. It indicates that the quantitative characteristic of management performance can be presented both as general utility $G U$ and as a system (process) characteristic $\mathrm{g}$, defined as a quality factor or $Q$-factor.

Therefore, there are two possible options for performance evaluation. Meanwhile, it is important to correctly evaluate resources expenses on the result achievement.

Analysis of efficiency of reference systems. If we define efficiency as a relation of performance to resource expenses, then we can consider two alternative options:

$$
\begin{aligned}
& \text { criterion } 1 E F_{1}=f_{r} / Z \rightarrow \max , \\
& \text { criterion } 2 E F_{2}=g / Z \rightarrow \max .
\end{aligned}
$$

The analysis showed that the second option, i.e., analysis of the system efficiency with regard to the criterion 2 (36), is more preferable than the first, because it provides higher elasticity $E F$ relative to the total utility $G U$. The relation $E F_{2 m} / E F_{1 m}=g / f_{r}$ in the mode of the golden ratio (when $g=2 ; f_{r}=0.618$ ) is equal to 3.23 .

The plot of dependency of efficiency $E F_{2}$ on dominant $f_{r}$ for reference systems (with different levels of quality factor $Q$-factor estimated $g$ ) is shown in Figure 4.

In the analysis of the model of process (system) efficiency, presented in Figure 4, it may seem as if the growth of the efficiency of reference systems is not limited at all. In fact, with the growth in the quality factor $Q$-factor estimated $g$, the system cost is increasing and according to the paper [118], this cost is proportional to $g$. Due to the high elasticity of the process efficiency relative to $Q$-factor estimated $g$, the system sustainability stock is decreasing and the possibility of bifurcation is increasing. The issue of the boundary of the efficient systems' sustainability is quite important but it requires individual consideration. 
Efficiency (EF2)

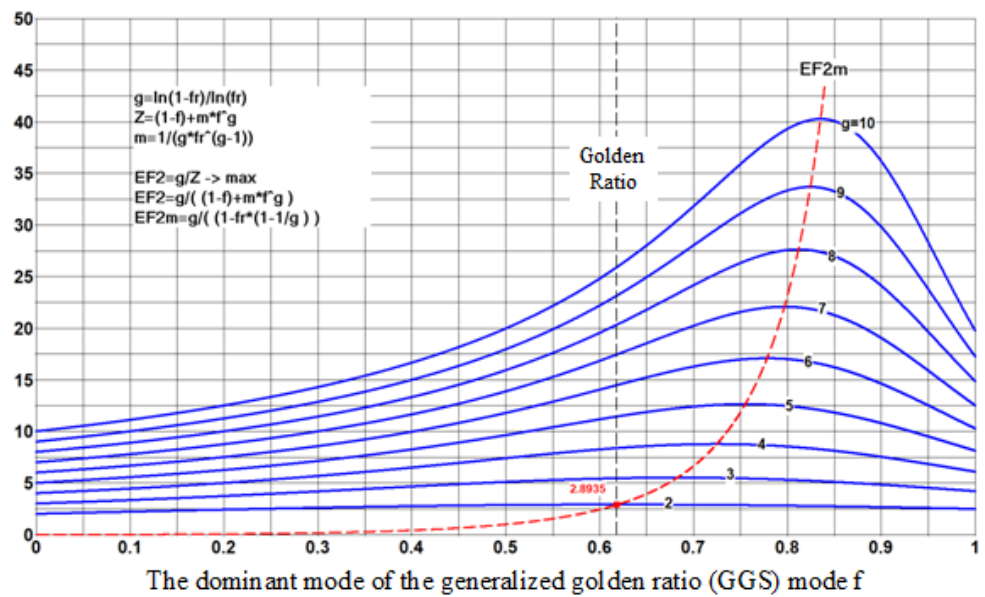

Figure 4. Model of process (system) efficiency $E F_{2}=f\left(f_{r}\right)$.

\subsection{Conceptual Model of Reference System Analysis}

Key properties of any rational systems are integrity and goal-orientation. System goals can differ but their main humanistic destination is a creation of some positive (utility). Management of complex systems is directed towards the growth of the positive. However, there are always forces that prevent the growth. Counteraction of multidirectional vectors forms dialectical results of complex systems' functioning. The antagonistic force of the utility is a system's sustainability.

With the growth of the consumed resource, the utility should increase, but at the same time the remaining resource is declining and this fact determines system sustainability and its ability to stably function. Therefore, the utility growth is not unlimited. In this situation the suggestion about some optimal (harmonious) system working mode occurs. The traditional approach supposes hidden (latent) work of some global mechanism, called the golden ratio or golden mean.

Lately the principle of the general golden ratio (GGR), established by Belarusian scientist E. M. Soroko [29] started to be used for analysis. Researchers of the V.A. Trapeznikov Institute of Management Problems of the Russian Academy of Science [119,120] created new scientific field: F-technologies (F-Fibonacci), successfully solving complex application problems of efficient management in the systems of various purposes.

The conceptual model (Figure 5) that we use also relies on the GGR principle and the first dialectic law. This model defines two new entities: normalized total utility and normalized sustainability.

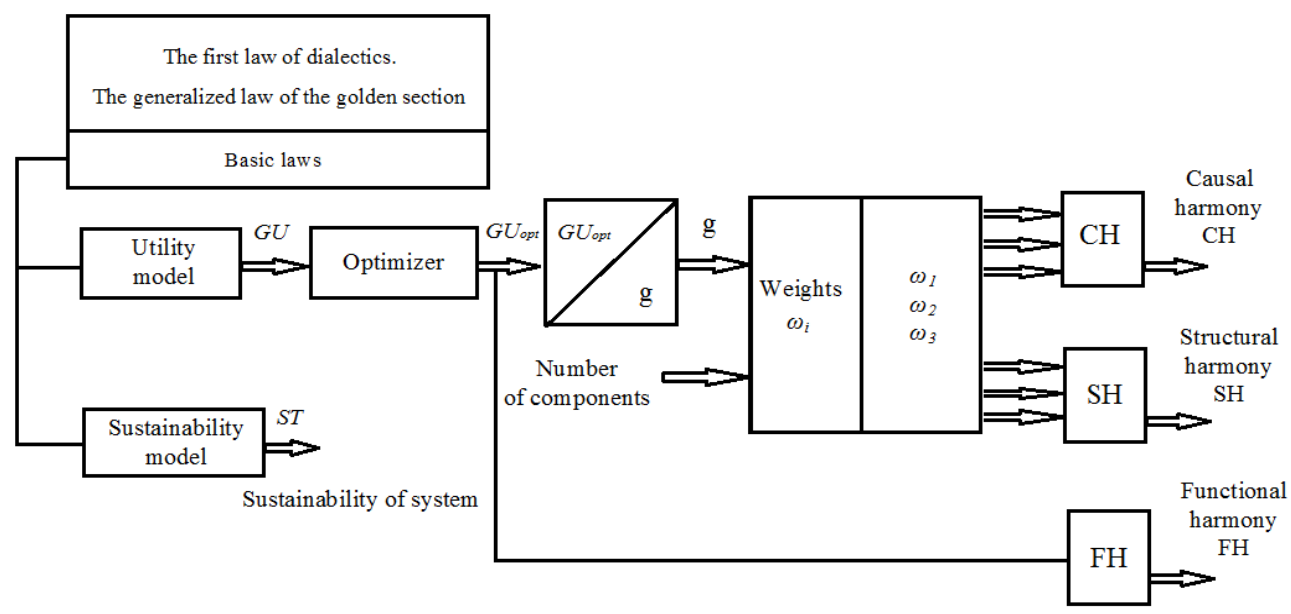

Figure 5. Conceptual model of complex system harmonycity formation. 
The research into these characteristics allows us to solve two important problems: the problem of the optimization of the system utility GU and the problem about the logical consequences generated by this optimization (casual, structural and functional system harmonies).

\subsection{Definition of the System Utility Function}

The system utility is characterized by the level of system functionality. Analytically it is set by the model of total utility GU.

In the structural identification of this model, we will assume that the first dialectic law works:

$$
\text { Positive }+ \text { negative }=\text { universum } \text {. }
$$

We interpret the positive as a saved resource and the negative as an under-received utility. After normalization we have

$$
a+b=1
$$

where

$a$-dominant, $a=1-x_{c}$;

$x_{c}$-the share of resource consumed on goal achievement;

$b$-subdominant; $b=1-G U$;

$\mathrm{GU}$ - the share of received utility relatively to maximal possible.

The GGR principle works as follows:

$$
\left(\frac{1}{a}\right)^{s}=\frac{a}{b}
$$

which gives (37):

$$
\left(\frac{1}{1-x_{c}}\right)^{s}=\frac{1-x_{c}}{1-G U_{n}}
$$

i.e.,

$$
G U_{n}\left(x_{c}\right)=1-\left(1-x_{c}\right)^{g}
$$

where

$g-Q$-factor-system quality indicator.

The plots of total utility functions for different values of the quality control $g$ are presented on Figure 6.

In Figure 6 the point $C$, corresponding to the classical golden ratio (under the condition $g=2)$, is highlighted. All sustainable solutions, conformed to GGR, are placed on the diagonal $Y_{2}=1-x_{c}$.

The analysis of extremely possible utility $P U$ (37) showed that GU meets the necessary requirements, i.e., it declines with the growth of consumed resource $x_{c}(39)$ :

$$
P U=d G U / d x_{c}=g \cdot\left(1-x_{c}\right)^{g-1}
$$


Normalized general utility GU

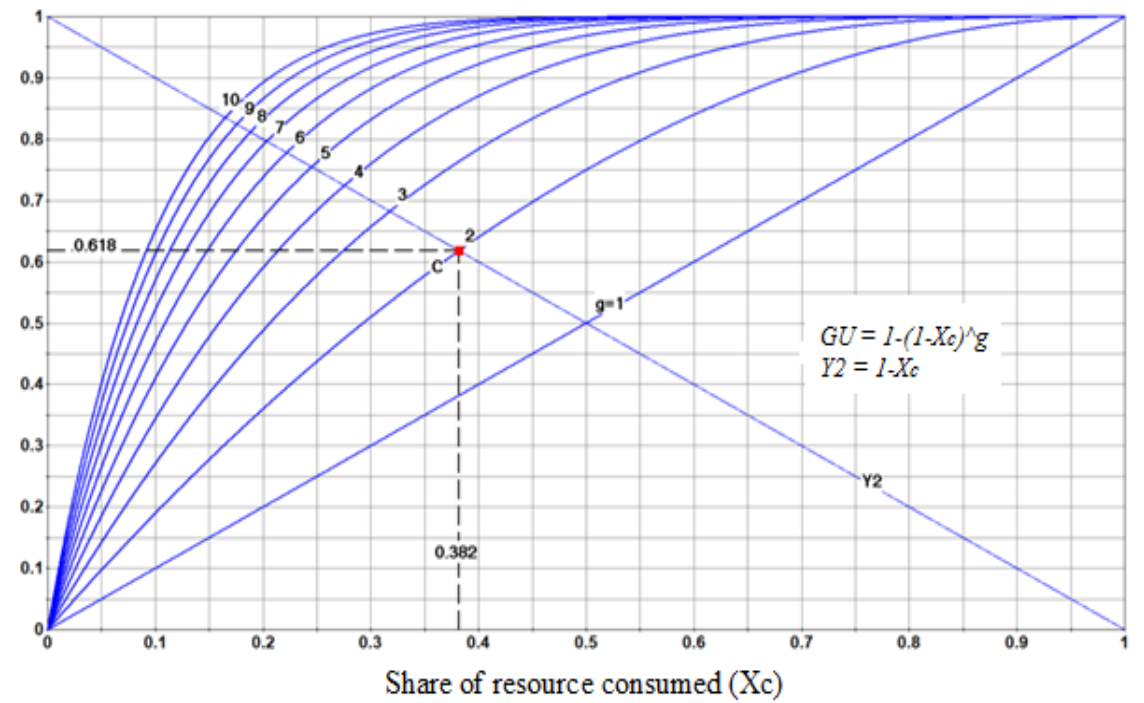

Figure 6. Plots of total utility functions $G U\left(x_{c}\right)$.

\subsection{Optimization of the Total Utility (Criteria of Optimality, System Harmonization)}

Taking into account the essence of the first dialectic law, we should expect a confrontation between the system positive and the system negative. The sustainable balance between them forms the system balance. Many authoritative scientists [121-123] suppose that system balance is identical to the concept of system harmony. In that point (denoted as $x_{o p t}$ ) two conditions should simultaneously meet:

- with regard to the first dialectic law, $a+b=1$, where $a=1-x_{c} ; b=1-G U$ ), the next condition should be satisfied

$$
a+b=\left(1-x_{c}\right)+(1-G U)=1 \text {, i.e., } G U=1-x_{c} .
$$

- with regard to GGR, GU $=1-\left(1-x_{c}\right)^{g}$. Therefore, in the optimum point (where $x_{c}=x_{o p t}$ ) we have

$$
1-x_{o p t}=1-\left(1-x_{o p t}\right)^{g}
$$

which implies that the quality factor equals to (40):

$$
g=\frac{\ln \left(x_{o p t}\right)}{\ln \left(1-x_{o p t}\right)}
$$

In the regime of classical golden ration, when $g=2, x_{o p t}=0.382$, substitution (40) into (37) gives an important result (41):

$$
G U_{o p t}=1-\left(1-x_{o p t}\right)^{\frac{\ln \left(x_{o p t}\right)}{\ln \left(1-x_{o p t}\right)}}=1-x_{o p t}
$$

Therefore,

$$
G U_{o p t}=1-x_{o p t}
$$

It means that:

- $\quad$ optimal solutions are always placed on the diagonal (42);

- $\quad$ system quality factor in the optimum point equals to $g=\frac{\ln \left(x_{o p t}\right)}{\ln \left(1-x_{o p t}\right)}$;

- $\quad$ work state in optimum should be considered as harmonious system state; 
- "weights" $\omega_{i}$ of system components, as shown in work [124], are predetermined by the system quality factor $\mathrm{g}(43)$ :

$$
\omega_{i}=\left(1-\frac{i-1}{n}\right)^{g}-\left(1-\frac{i}{n}\right)^{g}
$$

where

$n$-the number of components of the system under study;

$i$ - the rank of the component.

In the "golden ratio" regime (when $g=2$ ) formula (41) takes the form (44):

$$
\omega_{i}=\frac{2}{n}-\frac{(2 \cdot i-1)}{n^{2}}
$$

\subsection{Evaluation of the Complex Systems' Sustainability}

In recent times, in strategic management publications [125] the concept of sustainability is broadly used. Different authors variously interpret this concept [126]. The majority define it only from the economic or ecological point of view, but in fact this concept has a wider meaning. There is no unified point of the view on this issue yet. At the same time the sustainability concept is significant in system analysis. It predetermines the successfulness of functioning of an analyzed complex system.

Sustainability can be evaluated by different metrics. We will use the metric of the generalized golden ratio (GGR). As was shown earlier in Section 2.1:

$$
\text { Positive }+ \text { negative }=\text { universum } \text {. }
$$

The positive $(P)$ assumes the growth of system utility, while the negative $(N)$ is defined by the loss of system sustainability.

In the growth of the system utility the first summand-the Positive $(P)$-is dominant and after the normalization it will take the form of $G U_{o p t}$. $G U_{o p t}$ is total utility in the operating point. The second summand - the Negative $(\mathrm{N})$ - is a subdominant and it defines the share of the lost sustainability $\left(1-S T_{\text {opt. }}\right)$; here $S T_{\text {opt. }}$ is a normalized sustainability in the operating point.

We will use GGR in the form $\left(\frac{1}{G U_{o p t}}\right)^{s}=\frac{G U_{o p t}}{1-S T_{o p t}}$, and as a result we will have (45):

$$
S T_{o p t}=1-G U_{o p t}^{g}
$$

where

$g-Q$-factor-system quality indicator; $g=s+1$.

Analysis of the formula (45) allows us to make a significant conclusion: The growth of the utility is not unlimited: it is restrained by the loss of the sustainability. Sustainability (as an ability to execute prescribed functionality) is defined by the remaining resource and with its decline it also declines.

\subsection{Establishment of the Relation between System Sustainability and Its Utility}

The relation between the sustainability and the utility in the operating point (i.e., $x_{c}=x_{c \text { opt }}$ ) is characterized by the relation (45). In points $x_{c}$ the structure of this relation is inherited and the sustainability model can be represented in the form (46):

$$
S T\left(x_{c}\right)=1-\left[G U\left(x_{c}\right)\right]^{g}=1-\left[1-\left(1-x_{c}\right)^{g}\right]^{g}
$$

Plots of the functions $S T\left(x_{c}\right)$ and $G U\left(x_{c}\right)$ are presented in Figure 7. 


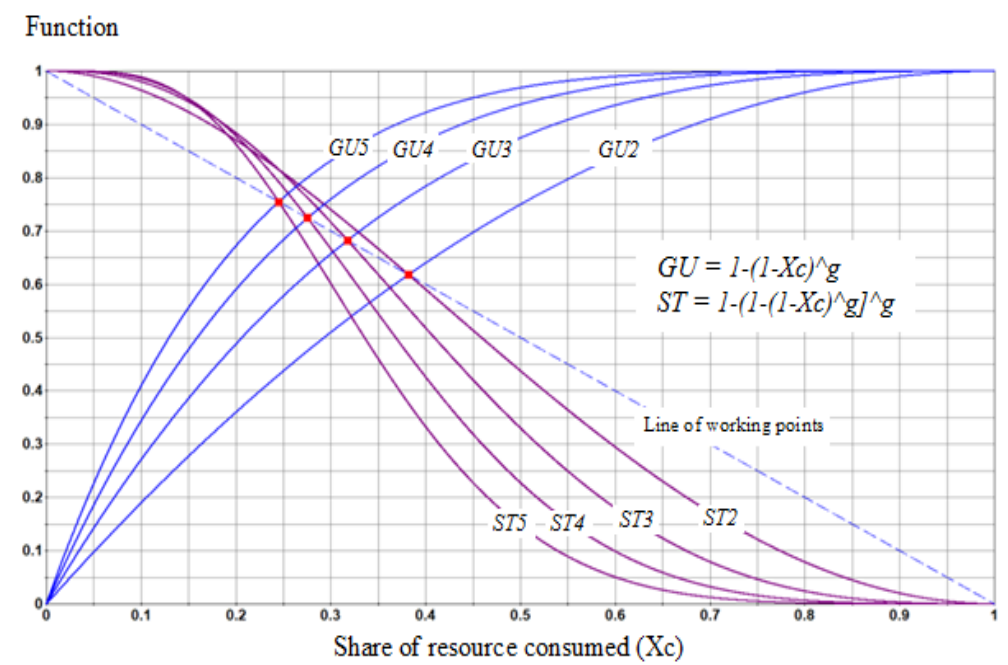

Figure 7. Plots of functions $G U\left(x_{c}\right)$ and $S T\left(x_{c}\right)$.

Operating points, corresponding to values of the quality factor $g=2,3,4$ and 5 are highlighted. The pair $G U_{2}$ and $G T_{2}$ belongs to the golden ratio regime $(g=2)$. In the operating point the condition

$$
G U_{2}\left(x_{c}\right)=S T_{c}\left(x_{c}\right)=0.618 \text { is met. }
$$

\subsection{Analysis of the Possibilities of System Sustainability Application}

There is a series of spheres in which arises a need to evaluate the sustainability level. From the positions of the PEST analysis [125] there are several types of sustainability:

- social;

- ecological;

- economic;

- technological (energetical);

- political.

In cases of sustainable urban mobility development, we should use vector (generalized) sustainability evaluation (47):

$$
S T=\sum_{i=1}^{n} \omega_{i} \cdot S T_{i}
$$

where

$S T_{i}$-sustainability in thei-sphere;

$\omega_{i}$-the "weight" coefficients, meeting the normalization condition $\sum_{i=1}^{n} \omega_{i}=1$.

\subsection{Harmonization of Complex Systems}

Usually, harmony is considered from three points of view [29]. Firstly, it is considered from the positions of the character and mechanism of harmonious impact of one system part on another (casual harmony). Secondly, it is considered as proportionality of the parts in the whole (structural harmony). Thirdly, it is considered as the mutual consistency and synchronicity of system components functioning (functional harmony). The authors agree with E. M. Soroko's point of view [29,115-117], consisting of the observation that system harmony is observed in the regime of the classical golden ratio, when the system quality factor equals $g=2$. 


\section{Identification of the Q-factor g of the Road Safety Provision System}

\subsection{The System Orderliness and Its Relation to the System Quality Factor}

In Section 2.1 it was shown that the base of the system orderliness is the structural sustainability. Maintenance of the system structural sustainability in the conditions of the negative impact of chaos is a consequence of the high level of the system orderliness. The system orderliness is identified by the features of the "weight" distribution Pareto charts or the system/process elements' significance in the formation of the system functioning result. It is quantitatively evaluated by the level of the curvature of the Lorenz curve of the Pareto chart.

The normalized Pareto chart is presented as a function of the normalized generalized utility $G U_{n}$, where $\mathrm{x}$ is the share of the used resource (Equation (1)). As it was shown above in Section 3.4, the Pareto chart is an increscent sum of "weights" $\omega_{i}$ of the components of the considered system. As it was shown in Equation (22), the "weight" coefficients $\omega_{i}$ are defined by the equation:

$$
\omega_{i}=D P_{i}-D P_{i-1}=\left(1-\frac{i-1}{n}\right)^{g}-\left(1-\frac{i}{n}\right)^{g}
$$

In addition, earlier in Section 2.1, in Equation (23) it was presented that the found "weight" coefficients $\omega_{i}$ relative structural entropy $H_{n}$, characterizing the level of orderliness (or structural perfection) of the process or the system:

$$
H_{n}=\left[-\sum_{i=1}^{n} w_{i} \cdot \ln \left(\omega_{i}\right)\right] / \ln (n)
$$

The utility function $G U(x)$ in the additive form can be presented as the sum of particular utility functions (or the sum of the shares of the contribution of $i$-components in the system result) (48):

$$
G U(x)=\sum_{i=1}^{n} G U_{i}(x)=\sum_{i=1}^{n} \omega_{i} \cdot\left[1-(1-x)^{g}\right]
$$

In this equation, $x$ is a share of the used resource and $g$ identifies the system quality factor. The determination of the relative structural entropy $H_{n}$ is important from the positions of the identification of the level of the system orderliness and the system quality factor $g$.

\subsection{Method of Definition of Relative Entropy of Road Safety Provision System}

Formula (41) connects "weights" $\omega_{i}$ of researched system components and the quality factor $g$. Consequently, this raises the question of the system itself, its components, their "weights" and the relative importance of each component to the formation of the system functioning result.

To consider the road safety provision system we need to define the size of the system (federal, regional, district, urban or microdistrict) and the cause-and-effect relationship of road accident rate formation.

\subsubsection{The Cause-and-Effect Model of Road Accident Rate Formation}

The cause-and-effect model for a road safety provision system is shown in Figure 8.

The goal of the analysis of the cause-and-effect model (Figure 8) is to establish the relationship between coefficients of the informational transfer of elements of the road accident rate formation process.

For the research into the examined process structure, we will use cybernetic modeling. The concept of cybernetic modeling is defined by V.I. Krutov et al. [127] in the following way: "cybernetic models are based on the receiving of relations between input and output 
function for some black box or grey box, representing examined an phenomenon, without disclosure of its inner structure".

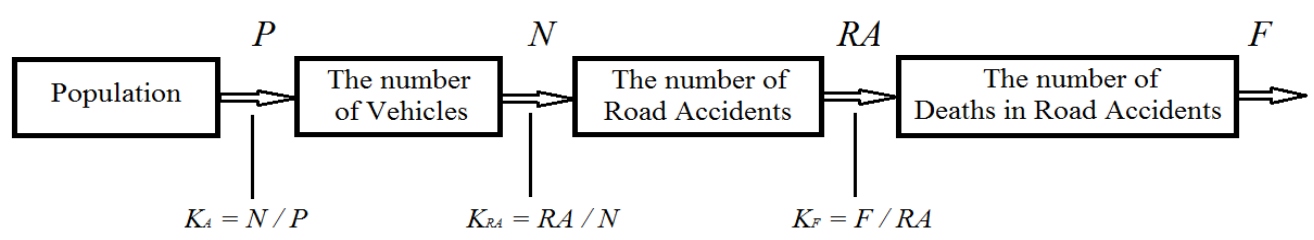

Figure 8. The cause-and-effect model of road accident rate formation.

We should pay attention not to the inner mechanism of each component of the examined process chain but only to coefficients $K_{i}$ of the informational transfer between elements of the cause-and-effect model. $K_{i}$ plays a special role in the analysis of the process model. It comprises the key characteristics of the elements of the complex system, the model of which is entirely defined by the behavior of its elements. The coefficient of the transfer of the $i$-element of the cause-and-effect model is a relation between its output $\left(A_{\text {out }}\right)$ and input $\left(A_{\text {in }}\right)$ :

$$
K_{i}=A_{\text {out }} / A_{\text {in }}
$$

With regard to the structure of the road accident rate mechanism (Figure 8) we distinguish 3 subprocesses:

- the formation of the vehicle fleet, determining the average annual intensity of road traffic (with the transfer coefficient $K_{A}=N / P$ );

- the formation of the road accidents (with the transfer coefficient $K_{R A}=R A / N$ );

- the formation of the deaths rate in road accidents, the number of the deceased in road accidents (with the transfer coefficient $K_{F}=F / R A$ );

\subsubsection{Determination of the Priorities of the Process Elements (ABC Analysis)}

The ABC analysis, based on the Pareto chart, is a tool of determination of the priorities of the examined process elements. The aim of the analysis is to identify main priorities. The essence of the $\mathrm{ABC}$ analysis consists of the search for the first and the second Pareto points (determining the position of the boundaries between $\mathrm{A}, \mathrm{B}$ and $\mathrm{C}$ areas).

To hold this analysis, it is necessary to preliminarily make a decision on 3 issues: decide what to define as the positive; choose necessary metric; prepare data.

For the first problem, it is obvious that the lower the transfer coefficient $K$ of the element, the more positive the result. Generally, for the whole cause-and-effect process chain we can say that the lower the value of the through transfer coefficient $K_{i}$, the more positive the system result.

In the next step we need to learn how to measure the positive, i.e., introduce the necessary metric. It is reasonable to use an indicator of the process $Q$ positive as a measure (49):

$$
Q_{i}=\ln \left(1 / K_{i}\right)
$$

Received results allow us to find "weak" elements in the chain of the cause-and-effect relations in the road accident rate formation process and set priorities in the road safety management sphere.

\subsubsection{Evaluation of the "Weight" Coefficients $\omega_{i}$}

Knowing the values of the positive of process elements $Q_{i}$, we determine the total process positive $Q(50)$ :

$$
Q=Q_{A}+Q_{R A}+Q_{F}=\ln \left(1 / K_{A}\right)+\ln \left(1 / K_{R A}\right)+\ln \left(1 / K_{F}\right)
$$


The "weight" coefficients $\omega_{i}$ show the share of each summand $Q_{i}$ in the total sum of the process positive $Q(51)$ :

$$
\omega_{i}=\frac{\ln \left(1 / K_{i}\right)}{\sum_{i=1}^{3} \ln \left(1 / K_{i}\right)}
$$

4.2.4. Evaluation of the Entropy as A Characteristic of the Orderliness of the Road Safety Provision System

The structure of the "weight" coefficients $\omega_{i}$ of the road safety provision process defines the level of the orderliness. The numerical characteristic of the orderliness level is an entropy $H(52)$ :

$$
H=-\sum_{i=1}^{n} \omega_{i} \cdot \ln \omega_{i}
$$

where

$n$-the number of system elements (in our case $n=3$ );

$\omega_{i}$-the "weight" coefficients, meeting the normalization condition $\sum_{i=1}^{n} \omega_{i}=1$.

Relative entropy $H_{n}$ is more visual and convenient from the positions of the application characteristic of the evaluation of the road safety provision system's orderliness (53):

$$
H_{n}=H / \ln (n)
$$

where

$n$-the number of system elements (in our case $n=3$ );

From now on we will use this characteristic to evaluate the orderliness of the road safety provision systems.

\subsection{The Method of the Determination of the Quality Factor of the Road Safety Provision System}

As was shown in Sections 2.4 and 4.1, value $g$ is an exponent of the exponential equation, identifying the curvature of the change in the Pareto chart cumulate. Equation (27), presented in Section 3.4, illustrates the meaning of the system quality factor $g$ :

$$
g=1+s=\frac{\ln \left(1-f_{r}\right)}{\ln \left(1-f_{s}\right)}
$$

By knowing the coordinates $f_{r}$ and $f_{s}$ of the curve, which identify the utility function $G U(x)$, we can determine the value of the quality factor of the system.

\section{Example of the Theoretical Solution of the Problem of the Evaluation of the System Harmonicity in Relation to the Road Safety Provision System}

As an example, we will provide results of the harmonic analysis of the complex systems in the road safety sphere, one of the key spheres of the urban mobility implementation. In this analysis the results of the authors' research relied on the database of the State Inspectorate for Road Traffic Safety [11].

The three "weight" coefficients of the rank Pareto chart are the subject of the analysis: "weight", characterizing the level of automobilization $\left(\omega_{A}\right)$; "weight", characterizing the level of road accidents $\left(\omega_{R A}\right)$ and "weight", characterizing the death rate $\left(\omega_{F}\right)$. The sum of "weights" meets the normalization condition $\sum_{i=1}^{3} \omega_{i}=1$

\subsection{Structural Harmony}

In reference systems, the "weight" coefficients are always determined (see relation (43), Figure 9). 


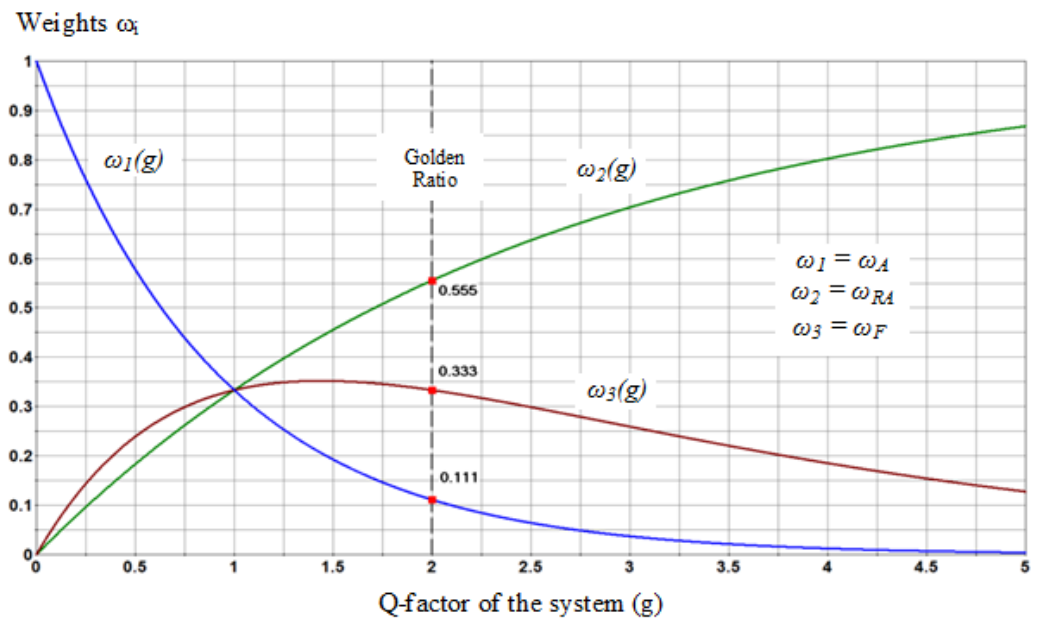

Figure 9. Structural harmony of the "weights" coefficients $\omega_{i}$.

In the golden ratio regime, when $g=2$, components" "weights" (Figure 9) correspond to the proportions (44) and when $n=3$ they are correspondingly equal: $\omega_{A}=0.111$; $\omega_{R A}=0.555 ; \omega_{F}=0.333$.

\subsection{Casual Harmony}

In the analysis it was taken into account that the level of automobilization $A$ is the root cause, while the number of road accidents and the number of deceased in road accidents are consequences of the automobilization $A$. Therefore, it is reasonable to present the casual harmony in the form of the dependency of the "weights" $\omega_{R A}$ and $\omega_{F}$ on the "weight" $\omega_{A}$ (Figure 10).

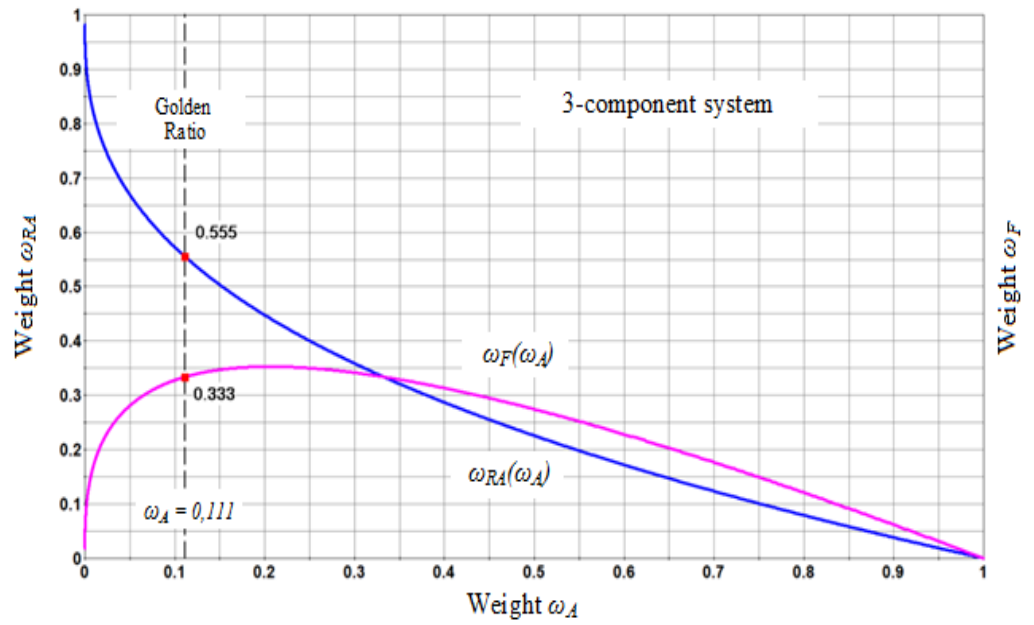

Figure 10. Casual harmony of the "weights" coefficients $\omega_{i}$.

The relation of the "weights" is of practical interest. It is presented in Figure 11.

\subsection{Functional Harmony}

According to Socrates [29], we connect functional harmony with the utility principle. The optimal level of the normalized utility is observed in the golden ratio conditions (Figure 12) and it is equal to 0.618. 


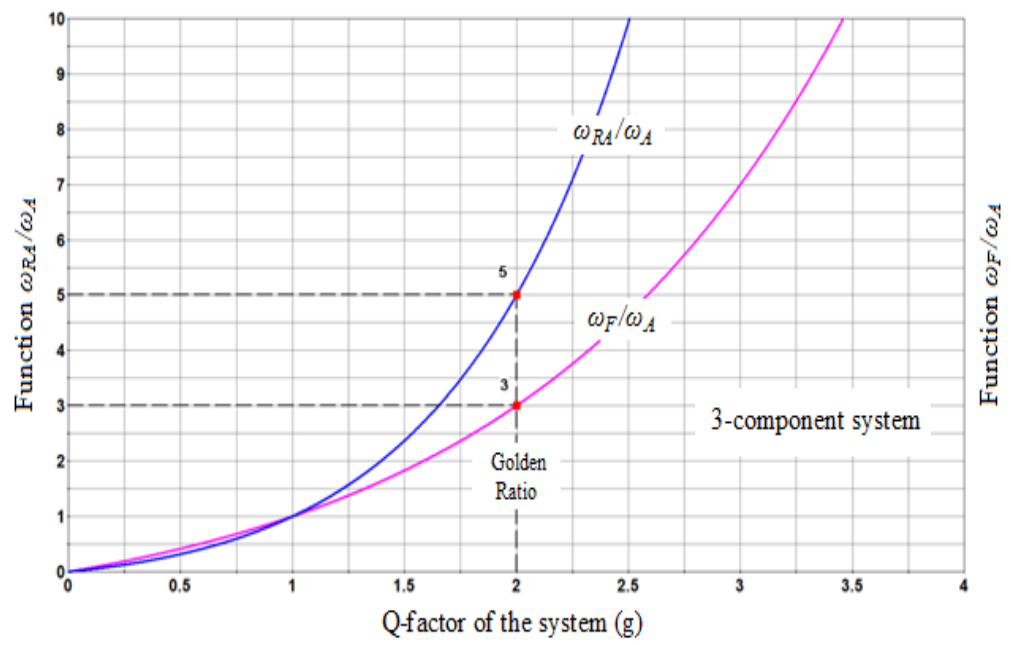

Figure 11. The relation of the "weights" coefficients $\omega_{i}$ for the road safety provision system case.

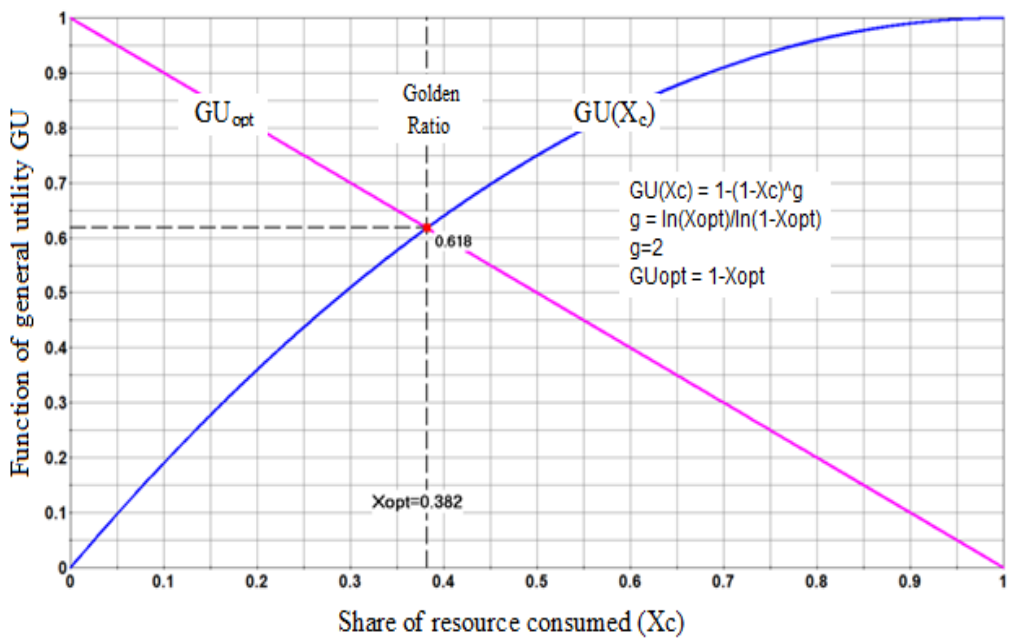

Figure 12. Functional harmony.

6. Quantitative Assessment of Changes in the Road Safety System Harmonicity in the Russian Federation

6.1. Assessment of the General Trend in Changes in the Road Safety System Harmonicity in Russia from 2006 to 2020

The data source was the official statistics of the State Inspectorate for Road Traffic Safety of the Russian Federation [11]. Over the past 15 years (2006-2020), the indicators of road safety in Russia have been constantly improving. A number of factors have contributed to this, such as a general increase in the transport culture of the country's population, a significant increase in the quality of the country's transport fleet and significant qualitative growth of the country's road transport infrastructure. It is also important that since 2006, a lot of attention has been paid to the issues of road safety provision by the Russian government $[9,10]$.

The result of the improvement in the overall situation in the transport sphere was a decrease in the annual number of accidents and deaths in road accidents in Russia over the past 15 years (Table 2). 
Table 2. Changes in the main road safety indicators in the Russian Federation from 2006 to 2020.

\begin{tabular}{|c|c|c|c|c|c|c|c|c|}
\hline \multirow{2}{*}{ Road Safety Indicators } & \multicolumn{8}{|c|}{ Numerical Values of Indicators By Year } \\
\hline & 2006 & 2008 & 2010 & 2012 & 2014 & 2016 & 2018 & 2020 \\
\hline Number of accidents, units & 228,309 & 217,557 & 199,083 & 203,597 & 199,720 & 173,694 & 168,099 & 137,662 \\
\hline $\begin{array}{l}\text { The number of people killed } \\
\text { in accidents, deceased people }\end{array}$ & 32,724 & 29,936 & 26,567 & 27,991 & 26,963 & 20,308 & 18,214 & 15,788 \\
\hline
\end{tabular}

The natural result of a long-term decrease in road traffic accident rate in Russia was a significant decrease in the relative entropy $H_{n}$ of the road safety system and an increase in its $Q$-factor $g$ (Table 3).

Table 3. Changes in relative entropy $H_{n}$ RSS and $Q$-factor $g$ values of the road safety system in Russia.

\begin{tabular}{ccccccccc}
\hline \multirow{2}{*}{ Characteristic } & \multicolumn{7}{c}{ Numerical Values of Indicators By Year } \\
\cline { 2 - 9 } & $\mathbf{2 0 0 6}$ & $\mathbf{2 0 0 8}$ & $\mathbf{2 0 1 0}$ & $\mathbf{2 0 1 2}$ & $\mathbf{2 0 1 4}$ & $\mathbf{2 0 1 6}$ & $\mathbf{2 0 1 8}$ & $\mathbf{2 0 2 0}$ \\
\hline $\begin{array}{c}\text { Relative entropy of the } \\
\text { road safety system } H_{n} \text { RSS }\end{array}$ & 0.862 & 0.847 & 0.831 & 0.817 & 0.797 & 0.780 & 0.775 & 0.755 \\
\hline $\begin{array}{c}\text { Q-factor of the road safety } \\
\text { system } g\end{array}$ & 1.956 & 2.027 & 2.098 & 2.166 & 2.262 & 2.346 & 2.374 & 2.465 \\
\hline
\end{tabular}

The dynamics of the change in $Q$-factor $g$ of the road safety system of the Russian Federation from 2006 to 2020 is very impressive.

At the same time, the ratio of "weight" coefficients $\omega_{i}$ changes over time. Based on these dynamics, it is possible to estimate changes in all three types of system harmony: structural, causal and functional.

Let us consider the actual data characterizing the "weight" coefficients $\omega_{i}$, and draw conclusions about the dynamics of the road safety system harmony in Russia over the past 15 years (2006-2020).

Table 4 presents data on the change in the numerical values of the "weight" coefficients $\omega_{i}$ from 2006 to 2020.

Table 4. Changes in the numerical values of the "weight" coefficients $\omega_{i}$ from 2006 to 2020.

\begin{tabular}{ccccccccccc}
\hline \multirow{2}{*}{ Characteristic } & \multicolumn{7}{c}{ Numerical Values of Indicators By Year } \\
\cline { 2 - 10 } & $\mathbf{2 0 0 6}$ & $\mathbf{2 0 0 8}$ & $\mathbf{2 0 1 0}$ & $\mathbf{2 0 1 2}$ & $\mathbf{2 0 1 4}$ & $\mathbf{2 0 1 6}$ & $\mathbf{2 0 1 8}$ & $\mathbf{2 0 2 0}$ \\
\hline$\omega_{A}$ & 0.170 & 0.155 & 0.143 & 0.134 & 0.120 & 0.104 & 0.098 & 0.093 \\
\hline$\omega_{R A}$ & 0.598 & 0.610 & 0.622 & 0.633 & 0.647 & 0.654 & 0.655 & 0.670 \\
\hline$\omega_{F}$ & 0.232 & 0.235 & 0.235 & 0.232 & 0.233 & 0.242 & 0.247 & 0.237 \\
\hline
\end{tabular}

Figure 13 shows the graphs of the dynamics of the "weight" coefficients of the road safety system in Russia from 2006 to 2020.

Figure 14 shows a comparison of the theoretical and actual dynamics of changes in the "weight" coefficients $\omega_{i}$ of the road safety system in Russia over a 15-year period.

The analysis of the dynamics of the values of the weight coefficients $\omega_{i}$ allows us to conclude that the value of "weight" $\omega_{A}$ has decreased almost by half over the past 15 years, the value of "weight" $\omega_{R A}$ has increased by $12 \%$, and the value of "weight" $\omega_{F}$ has increased by $6 \%$ from 2016 to 2018 . However, in 2020, the "weight" $\omega_{F}$ significantly dropped again. This happened due to a significant increase in the severity of road accidents in 2020. The reason is the increase in the speed of vehicle movement in Russia in 2020 in the conditions of a relative rarefaction of the traffic flow associated with pandemic restrictions on the population mobility. 


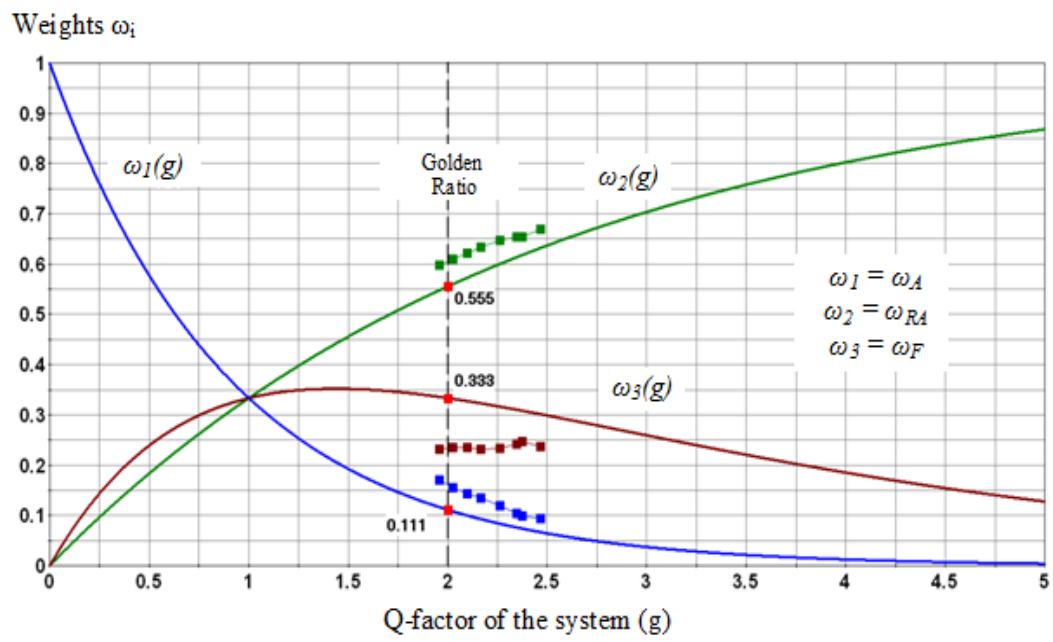

Figure 13. The actual dynamics of the "weights" coefficients of the road safety system in Russia.

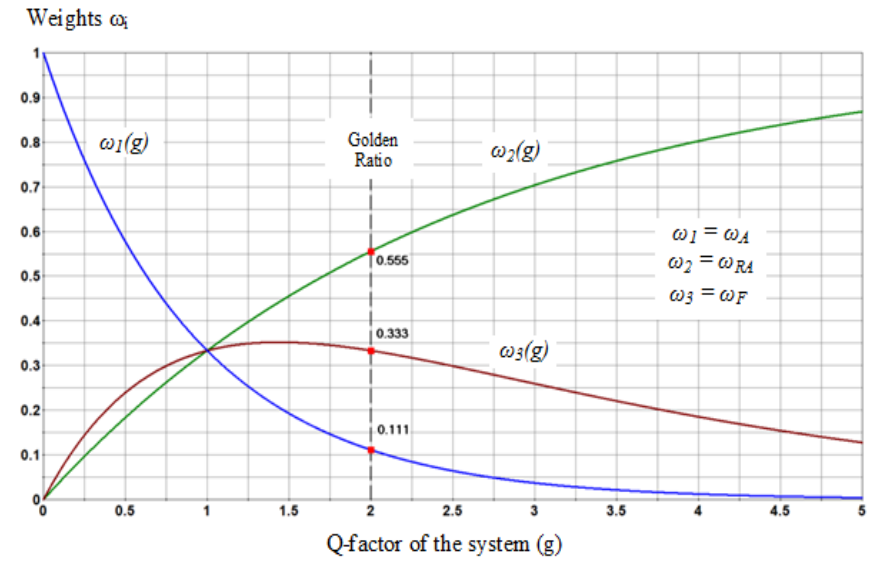

(a). Theoretical graph

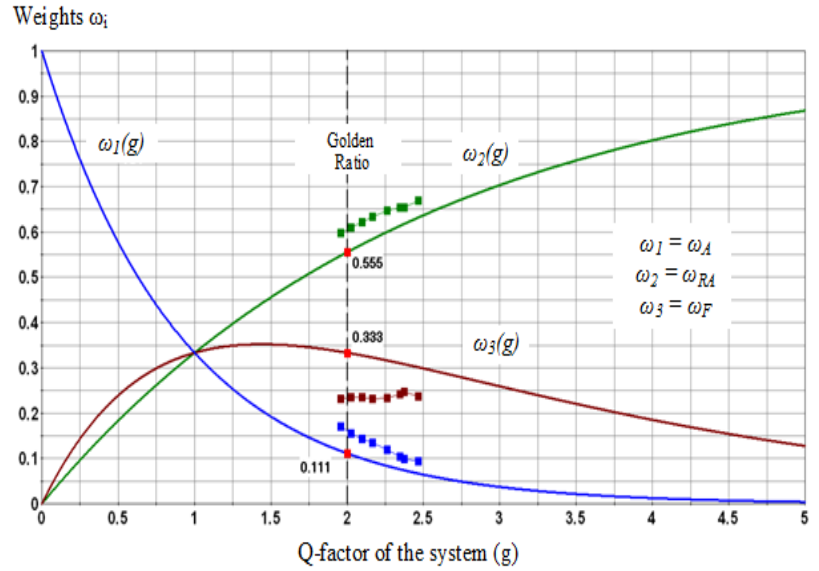

(b). Empirical graph

Figure 14. Comparison of the theoretical and actual dynamics of changes in the "weights" coefficients of the road safety system in Russia over a 15-year period (2006-2020).

This is also evidenced by the statistics of penalties for violating the requirements of traffic rules and the share of those that fall on violation of the requirements of the speed limits (Table 5).

Table 5. General statistics of penalties for violators of traffic rules in Russia (2016-2020).

\begin{tabular}{cccccc}
\hline \multirow{2}{*}{ Indicator } & \multicolumn{4}{c}{ Numerical Values of Indicators By Year } \\
\cline { 2 - 6 } & $\mathbf{2 0 1 6}$ & $\mathbf{2 0 1 7}$ & $\mathbf{2 0 1 8}$ & $\mathbf{2 0 1 9}$ & $\mathbf{2 0 2 0}$ \\
\hline The number of penalties, mln. units & 87.1 & 108.7 & 131.3 & 142.1 & 167.0 \\
\hline $\begin{array}{c}\text { Of these, for violation of the speed } \\
\text { limit, mln. units }\end{array}$ & 54.0 & 74.4 & 92.2 & 101.8 & 71.6 \\
\hline $\begin{array}{c}\text { The share of speed limit violations in } \\
\text { the total number of violations, } \%\end{array}$ & 62.0 & 68.4 & 70.2 & 74.2 \\
\hline
\end{tabular}

The data analysis in Table 5 shows that over the past 5 years in Russia, not only the number of penalties for violating traffic rules, but also the share of speed violations has increased. This indirectly indicates an increase in the quality of Russian roads and an 
improvement in the system of monitoring the speed limits of traffic flows. It is known that at the end of 2020, about 19,000 automated complexes for photo-video recording of traffic violations by drivers were used in Russia.

Figure 15 shows a comparison of the theoretical and actual dynamics of causal harmony of the road safety provision system in Russia over a 15-year period.

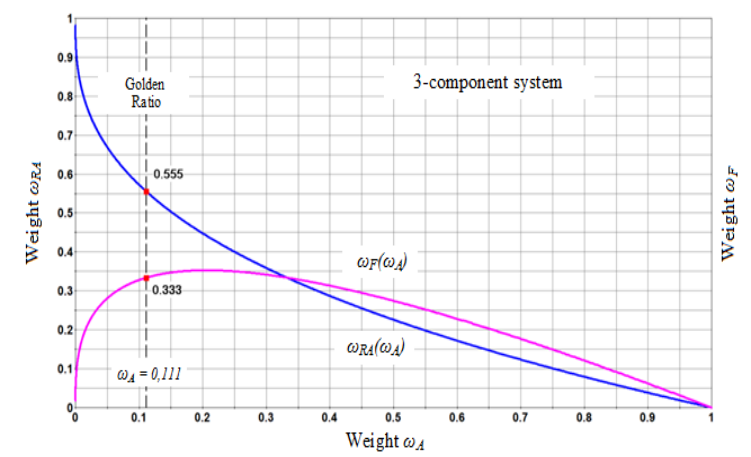

(a). Theoretical graph

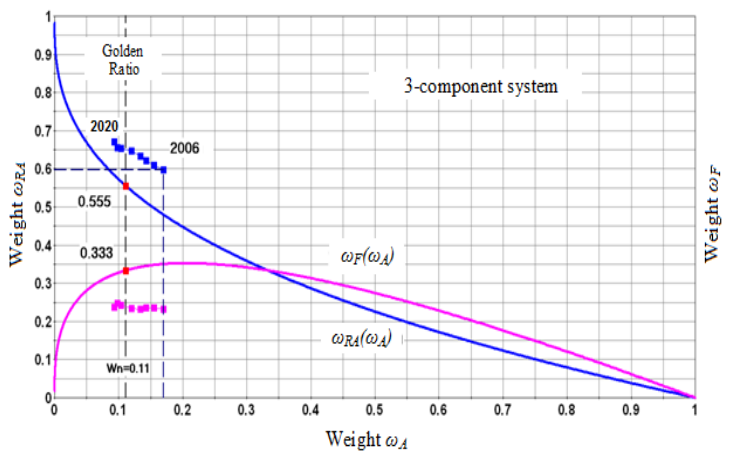

(b). Empirical graph

Figure 15. Comparison of the theoretical and actual dynamics of causal harmony of the road safety system in Russia over a 15-year period (2006-2020).

The functionality of the road safety system is estimated by the ratio of the actual level of normalized functional utility $G U_{n}$ and the share of consumed resource $X_{c}$, and is actually identified by the coordinate of the first Pareto point on the graph $G U_{n}=f\left(X_{c}\right)$. Table 6 shows the data on changes in the numerical values of the actual level of the normalized functional utility $G U_{n} R S S$ of the Russian road safety provision system.

Table 6. Changes in the numerical values of the normalized general utility GU $U_{n}$ RSS of the Russian RSS from 2006 to 2020.

\begin{tabular}{ccccccccc}
\hline \multirow{2}{*}{ Characteristic } & \multicolumn{7}{c}{ Numerical Values of Indicators By Year } \\
\cline { 2 - 7 } & $\mathbf{2 0 0 6}$ & $\mathbf{2 0 0 8}$ & $\mathbf{2 0 1 0}$ & $\mathbf{2 0 1 2}$ & $\mathbf{2 0 1 4}$ & $\mathbf{2 0 1 6}$ & $\mathbf{2 0 1 8}$ & $\mathbf{2 0 2 0}$ \\
\hline $\begin{array}{c}\text { Normalized general utility } \\
\text { GU } U_{n \text { RSS }}\end{array}$ & 0.615 & 0.620 & 0.626 & 0.631 & 0.639 & 0.644 & 0.646 & 0.652 \\
\hline
\end{tabular}

Figure 16 shows the dynamics of the actual numerical values of the normalized general utility $G U_{n} R S S$ of the Russian road safety provision system from 2006 to 2020.

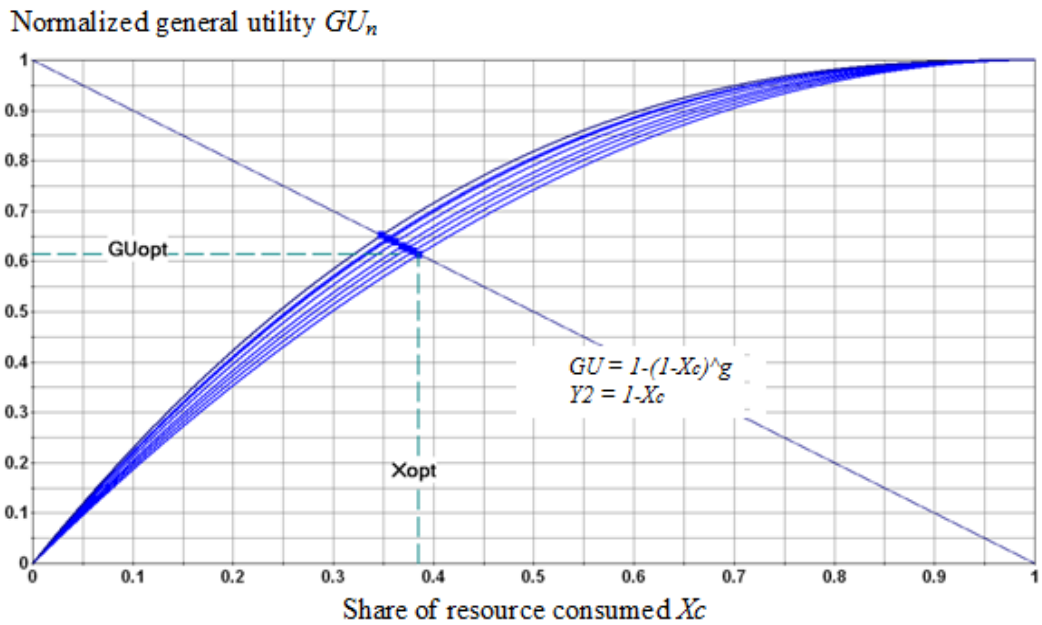

Figure 16. The actual dynamics of the values of the normalized general utility $G U_{n}$. 
Comparing the data in Figure 16 with the known optimal value of the normalized utility $G U_{o p t}=0.618$, it is easy to conclude about the current state of the Russian road safety provision system harmonicity.

6.2. Comparison of the Road Safety System Harmonicity in Russia during the COVID Restriction Period (2020) and during the Pre-COVID Period (2019)

COVID-restrictions on mobility of all types (pedestrian, transport and general) have very seriously affected the change in all characteristics that define the process of road traffic accident formation in Russia.

Table 7 presents data describing the process of road accident rate formation in Russia in 2019 and 2020.

Table 7. Numerical values of the characteristics of the causal path of road traffic accident formation in Russia before (2019) and during (2020) the COVID-19 pandemic.

\begin{tabular}{|c|c|c|c|c|}
\hline Year & $\begin{array}{c}\text { Population of Russian } \\
\text { Federation } \\
\text { (on 1 January the } \\
\text { Following Year), People }\end{array}$ & $\begin{array}{l}\text { The Average Annual } \\
\text { Number of the Fleet of } \\
\text { Vehicles of the Russian } \\
\text { Federation, Units }\end{array}$ & $\begin{array}{l}\text { Annual Number of Road } \\
\text { Accidents in the Russian } \\
\text { Federation, Case/Year }\end{array}$ & $\begin{array}{c}\text { The Annual Number of Deaths } \\
\text { in Road Accidents in the } \\
\text { Russian Federation, } \\
\text { Deceased/Year }\end{array}$ \\
\hline 2019 & $146,748,590$ & $61,739,156$ & 164,358 & 16,981 \\
\hline \multirow[t]{2}{*}{2020} & $146,171,015$ & $62,721,765$ & 137,662 & 15,788 \\
\hline & \multicolumn{3}{|c|}{ Absolute change, unit } & \\
\hline \multirow{2}{*}{$\Delta_{2020 / 2019}$} & $-577,575$ & $+982,609$ & $-26,696$ & -1193 \\
\hline & \multicolumn{3}{|c|}{ Relative change, $\%$} & \\
\hline$\Delta_{2020 / 2019}, \%$ & -0.39 & +1.59 & -16.25 & -7.02 \\
\hline
\end{tabular}

Tables 8 and 9 present the intermediate (according to the methodology of Section 4.2 of the article) and final results of calculating the relative entropy of the Russian road safety system $H_{n}$ RSS RF in 2019 and 2020.

Table 8. Intermediate and final results of calculating the relative entropy $H_{n}$ RS SRF of the Russian road safety system in 2019.

\begin{tabular}{|c|c|c|c|}
\hline \multicolumn{4}{|c|}{$\begin{array}{c}\text { Numerical Values of the Elements of the Three-Link Mechanism of Informational Transformation of the Road Safety System in the Russian } \\
\text { Federation, } 2019\end{array}$} \\
\hline $\begin{array}{c}\mathrm{Y}_{1}- \\
\text { Country population }\end{array}$ & $\begin{array}{c}\mathrm{Y}_{2}- \\
\text { Size of vehicle fleet }\end{array}$ & $\begin{array}{l}\qquad \mathrm{Y}_{3}- \\
\text { Annual number of road accidents }\end{array}$ & $\begin{array}{c}\mathrm{Y}_{4}- \\
\text { Annual number of deaths in road } \\
\text { accidents }\end{array}$ \\
\hline $146,748,590$ & $61,739,56$ & 164,358 & 16,981 \\
\hline \multicolumn{4}{|c|}{$K_{i}$ numerical values } \\
\hline$K_{A}$ & & & $K_{F}$ \\
\hline $61,739,156 / 146,748,590=0.4207$ & 164,35 & $156=0.0026$ & $16,981 / 164,358=0.1033$ \\
\hline \multicolumn{4}{|c|}{ Numerical values of the positive $Q_{i}=\ln \left(1 / K_{i}\right)$} \\
\hline 0.8658 & & & 2.2700 \\
\hline \multicolumn{4}{|c|}{ Numerical values of relative "weight" of the positive $\omega_{\mathrm{i}}\left(Q_{i}\right)$} \\
\hline 0.096 & & & 0.250 \\
\hline \multicolumn{4}{|c|}{ Numerical values $\left(\ln \omega_{i}\right)$} \\
\hline-2.3485 & & & -1.3846 \\
\hline \multicolumn{4}{|c|}{ Numerical values $\left(\omega_{i} \cdot \ln \omega_{i}\right)$} \\
\hline-0.2243 & & & -0.3467 \\
\hline \multicolumn{4}{|c|}{ Numerical value of absolute entropy $H_{R S S} R F=0.8487$} \\
\hline \multicolumn{4}{|c|}{ Numerical value of relative entropy $H_{n} R S S R F=0.7726$} \\
\hline
\end{tabular}


Table 9. Intermediate and final results of calculating the relative entropy $H_{n} R S S$ RF of the Russian road safety system in 2020.

\begin{tabular}{|c|c|c|c|}
\hline \multicolumn{4}{|c|}{$\begin{array}{c}\text { Numerical Values of the Elements of the Three-Link Mechanism of Informational Transformation of the Road Safety System in the Russian } \\
\text { Federation, } 2020\end{array}$} \\
\hline $\begin{array}{c}\mathrm{Y}_{1}- \\
\text { Country population }\end{array}$ & $\begin{array}{l}\mathrm{Y}_{2}- \\
\text { Number of vehicle fleet }\end{array}$ & $\begin{array}{c}\mathrm{Y}_{3}- \\
\text { Annual number of road accidents }\end{array}$ & $\begin{array}{c}\mathrm{Y}_{4}- \\
\text { Annual number of deaths in road } \\
\text { accidents }\end{array}$ \\
\hline $146,171,015$ & $62,721,765$ & 137,662 & 15,788 \\
\hline \multicolumn{4}{|c|}{$K_{i}$ numerical values } \\
\hline$K_{A}$ & \multicolumn{2}{|c|}{$K_{R A}$} & $K_{F}$ \\
\hline $62,721,765 / 146,171,015=0.4291$ & \multicolumn{2}{|c|}{$137,662 / 62,721,765=0.0022$} & $15,788 / 137,662=0.1147$ \\
\hline \multicolumn{4}{|c|}{ Numerical values of the positive $Q_{\mathrm{i}}=\ln \left(1 / K_{i}\right)$} \\
\hline \multirow[t]{2}{*}{0.8461} & \multicolumn{2}{|c|}{6.1217} & 2.1656 \\
\hline & \multicolumn{3}{|c|}{ Numerical values of relative "weight" of the positive $\omega_{\mathrm{i}}\left(Q_{i}\right)$} \\
\hline \multirow[t]{2}{*}{0.093} & \multicolumn{2}{|c|}{0.670} & 0.237 \\
\hline & \multicolumn{2}{|c|}{ Numerical values $\left(\ln \omega_{i}\right)$} & \\
\hline \multirow[t]{2}{*}{-2.34791} & \multicolumn{2}{|c|}{-0.4001} & -1.4393 \\
\hline & \multicolumn{2}{|c|}{ Numerical values $\left(\omega_{i} \cdot \ln \omega_{i}\right)$} & \\
\hline \multirow[t]{3}{*}{-0.2204} & \multicolumn{2}{|c|}{-0.2682} & -0.3413 \\
\hline & \multicolumn{3}{|c|}{ Numerical value of absolute entropy $H_{R S S} R F=0.8298$} \\
\hline & \multicolumn{2}{|c|}{ Numerical value of relative entropy $H_{n} R S S R F=0.7553$} & \\
\hline
\end{tabular}

On the basis of the numerical values of $H_{n} R S S R F-2019=0.7726$ and $H_{n} R S S R F-2020=0.7553$ we determined the appropriate $Q$-factor levels of the road safety system for the versions of 2019 and 2020.

$Q$-factor of the road safety system in the Russian Federation in $2019 g$ RSS RF-2019 $=2.3754$, and its analogue for $2020 \mathrm{~g} R S S R F-2020=2.4646$.

The calculations show that the changes in the Russian road safety system that occurred during COVID restrictions (2020) ensured a decrease in its relative entropy $\mathrm{H}_{n}$ by $2.24 \%$, from $H_{n \text { RSS } 2019}=0.7726$ to $H_{n}$ RSS $2020=0.7553$. The orderliness of the road safety system in Russia has improved.

The $Q$-factor of the Russian road safety system $g$ RSS increased by $3.75 \%$ during COVID restrictions (2020).

Normalized general utility $G U_{n}$ RSS increased by $0.46 \%$ from 2019 to $2020\left(G U_{n} R S S 2019\right.$ $=0.649$ and $G U_{n}$ RSS $2019=0.652$ ).

\section{Conclusions}

During the research it was established that the $Q$-factor $g$ of the Russian road safety provision system changed from $g 2006=1.9565$ to $g 2020=2.4646$. This promotes the decline of the relative entropy of the Russian road safety provision system from $H_{n}$ RSS $2006=0.8623$ to $H_{n}$ RSS $2020=0.7553$. The deep reason for that change was the modification of the relation between "weights" or the significance of the contribution of different elements of the cause-and-effect chain in the formation of the factual level of the road accident rate in Russia in the last 15 years.

The main conclusion is that the harmonicity of the Russian road safety provision system, assessed by the normalized functional general utility $G U_{n}$, has been increased and it already exceeded the level of harmonious reference systems $G U_{n}=0.618$.

Actually, the normalized functional general utility $G U_{n} R S S$ of the Russian road safety provision system increased from $G U_{n}$ RSS $2006=0.615$ to $G U_{n} R S S 2020=0.652$ (by 6.0\%) from 2006 to 2020. Simultaneously, the share of the normalized used resource $X_{n}$ declined. That allowed us to make a conclusion about a significant improvement in the balance "efficiency-quality" of the Russian road safety provision system. The COVID lockdown played a positive role in this process. The harmonicity of the Russian road safety provision 
system, assessed by the normalized general utility $G U_{n}$ RSS, increased by $0.46 \%$ from 2019 to 2020 .

It is important to note that the methodology of the quantitative assessment of the system harmonicity can be applied to a variety of spheres of human activity. The road safety system is just one example. Exactly the same calculations can be carried out to assess the harmonicity of the functioning of a variety of socio-technical and socio-cultural systems.

Author Contributions: Conceptualization, A.I.P. and V.I.K.; methodology, V.I.K.; software, A.I.P., V.I.K. and D.A.P.; validation, A.I.P. and V.I.K.; formal analysis, A.I.P. and D.A.P.; investigation, A.I.P.; resources, A.I.P.; data curation, A.I.P. and D.A.P.; writing-original draft preparation, A.I.P. and V.I.K.; writing-review and editing, A.I.P. and D.A.P.; visualization, A.I.P., V.I.K. and D.A.P.; supervision, A.I.P.; project administration, A.I.P.; funding acquisition, A.I.P. All authors have read and agreed to the published version of the manuscript.

Funding: This research was funded by the Russian Ministry of Education and Science, grant number 0825-2020-0014, 2020-2022. «New patterns and solutions for the functioning of urban transport systems in the paradigm "Transition from owning a personal car to mobility as a service"».

Institutional Review Board Statement: Not applicable.

Informed Consent Statement: Not applicable.

Data Availability Statement: Not applicable.

Acknowledgments: 1 . The authors would like to thank the Russian Ministry of Education and Science on the project: «New patterns and solutions for the functioning of urban transport systems in the paradigm "Transition from owning a personal car to mobility as a service"» (No. 0825-2020-0014, 2020-2022). 2. The authors would like to thank the anonymous reviewers for their very useful suggestions.

Conflicts of Interest: The authors declare no conflict of interest.

\section{References}

1. Schwab, K.; Malleret, T. COVID-19. The Great Reset; World Economic Forum: Cologny, Geneva, 2020; 212p.

2. TomTom Traffic Index. Available online: https://www.tomtom.com/en_gb/traffic-index/ (accessed on 9 August 2021).

3. Sharifi, A.; Khavarian-Garmsir, A.R. The COVID-19 pandemic: Impacts on cities and major lessons for urban planning, design and management. Sci. Total Environ. 2020, 749, 142391. [CrossRef]

4. Rutz, C.; Loretto, M.C.; Bates, A.E.; Davidson, S.C.; Duarte, C.M. COVID-19 lockdown allows researchers to quantify the effects of human activity on wildlife. Nat. Ecol. Evol. 2020, 4, 1156-1159. [CrossRef]

5. Road Safety Annual Report. 2020. Available online: www.itf-oecd.org/road-safety-annual-report-2020 (accessed on 10 August 2021).

6. Resolution A/RES/74/299. Improving Global Road Safety. Available online: un.org $\backslash T 1 \backslash$ guilsinglrightpga/74---uploads--Resolution-Road-Safety.pdf (accessed on 10 August 2021).

7. Voas, R.B.; Fell, J.C.; McKnight, A.S.; Sweedler, B.M. Controlling Impaired Driving Through Vehicle Programs: An Overview. Traffic Inj. Prev. 2004, 5, 292-298. [CrossRef]

8. Amador, L.; Willis, C.J. Demonstrating a Correlation between the Maturity of Road Safety Practices and Road Safety Incidents. Traffic Inj. Prev. 2014, 15, 591-597. [CrossRef]

9. Mayorov, V.I.; Sevryugin, V.E. International experience of developing complex target programs of road users' safety. Criminol. J. Baikal Natl. Univ. Econ. Law 2015, 9, 766-776. (In Russian) [CrossRef]

10. Decree of the Government of the Russian Federation of 8.01.2018, No 1-r, On Approval of the Road Safety Strategy in the Russian Federation for 2018-2024. Available online: https:/ / docs.cntd.ru/document/556323639 (accessed on 11 August 2021).

11. The Official Website of the State Traffic Inspectorate of the Russian Federation. Indicators of the State of Road Safety. Available online: http:/ / stat.gibdd.ru/ (accessed on 11 August 2021).

12. Benedict, R. Synergy: Some Notes of Ruth Benedict. Am. Anthropologist. New Ser. 1970, 72, 320-333.

13. Maslow, A.H. Synergy in the Society and in the Individual. J. Individ. Psychol. 1964, 20, 153.

14. Evans, P. Government action, social capital and development: Reviewing the evidence on synergy. World Dev. 1996, 24, 1119-1132. [CrossRef]

15. Evans, P.; Berkeley, C.A. (Eds.) State-Society Synergy: Government and Social Capital in Development; Institute for International Studies: Berkeley, CA, USA, 1996.

16. Hauert, C.; Michor, F.; Nowak, M.A.; Doebeli, M. Synergy and discounting of cooperation in social dilemmas. J. Theor. Biol. 2006, 239, 195-202. [CrossRef] [PubMed] 
17. Jaffe, K. Quantifying social synergy in insect and human societies. Behav. Ecol. Sociobiol. 2010, 64, 1721-1724. [CrossRef]

18. Prigogine, I.; Stengers, I. Order out of Chaos: Man's New Dialogue with Nature; A Bantam Book: Toronto, ON, Canada; New York, NY, USA; London, UK; Sydney, Australia, 1984; 349p.

19. Prigogine, I. The philosophy of instability. Futures 1989, 21, 396-400. [CrossRef]

20. Nicolis, G.; Prigogine, I. Self-Organization in Nonequilibrium Systems; John Wiley \& Sons: New York, NY, USA, 1977; 491p.

21. Othmer, H.G. Self-Organization in Nonequilibrium Systems (G. Nicolis and I. Prigogine). SIAM Rev. 1982, 24, 483-485. [CrossRef]

22. Haken, H. The Science of Structure: Synergetics; Prentice Hall: New York, NY, USA, 1984.

23. Haken, H. Synergetics: An Introduction; Springer Ser. Synergetics: Berlin/Heidelberg, Germany, 1983.

24. Haken, H. Advanced Synergetics; Springer Ser. Synergetics: Berlin/Heidelberg, Germany, 1987.

25. Liening, A. Synergetics-Fundamental Attributes of the Theory of Self-Organization and Its Meaning for Economics. Mod. Econ. 2014, 5, 841-847. [CrossRef]

26. Yakimtsov, V.V. History and development of Haken's synergetics. Sci. Bull. UNFU 2018, 28, 119-125. [CrossRef]

27. Kurdyumov, S.P.; Malinetskii, G.G. Synergetics-Theory of Self-Organization. Ideas, Methods, Perspectives; Nauka: Moscow, Russia, 1983; 280p. (In Russian)

28. Kurdyumov, S.P.; Malinetskii, G.G. Prologue. Synergetics and System Synthesis. Looking to the Third Millennium; Nauka: Moscow, Russia, 2002; 420p. (In Russian)

29. Soroko, E.M. Golden Sections, Processes of Self-Organization and Evolution of Systems: An Introduction to the General Theory of Harmony of Systems, 4rd ed.; Book House "Librocom": Moscow, Russia, 2012; 264p. (In Russian)

30. Gordon, J.E. The epidemiology of accidents. Am. J. Public Health 1949, 39, 504-515. [CrossRef]

31. Gibson, J.J. The Contribution of Experimental Psychology to the Formulation of the Problem of Safety-A Brief for Basic Research. Behavioural Approaches to Accident Research; Assoc. for the Aid of Crippled Children: New York, NY, USA, 1961 ; pp. 77-89.

32. Haddon, $\mathrm{W}$. The changing approach to the epidemiology, prevention, and amelioration of trauma: The transition to approaches etiologically rather than descriptively based. Am. J. Public Health 1968, 58, 1431-1438. [CrossRef]

33. Haddon, W. A logical framework for categorizing highway safety phenomena and activity. J. Trauma 1972, 12, 193-207. [CrossRef] [PubMed]

34. Haddon, W. Energy damage and 10 countermeasure strategies. J. Trauma Inj. Infect. Crit. Care 1973, 13, 321-331. [CrossRef] [PubMed]

35. Haddon, W. Options for the prevention of motor vehicle crash injury. Isr. J. Med. Sci. 1980, 16, 45-65.

36. Von Bertalanffy, L. General System Theory: Foundations, Development, Applications; Penguin: London, UK, 1968.

37. Johansson, R. Vision Zero-Implementing a policy for traffic safety. Saf. Sci. 2009, 47, 826-831. [CrossRef]

38. Larsson, P.; Dekker, S.W.; Tingvall, C. The need for a systems theory approach to road safety. Saf. Sci. 2010, 48, 1167-1174. [CrossRef]

39. Szymanek, A. System Approach in Road Safety Studies. Commun. Sci. Lett. Univ. Zilina 2020, 22, 201-210. [CrossRef]

40. Hughes, B.P.; Newstead, S.; Anund, A.; Shu, C.C.; Falkmer, T. A review of models relevant to road safety. Accid. Anal. Prev. 2015, 74, 250-270. [CrossRef]

41. Smeed, R.J. Some statistical aspects of road safety research. J. R. Stat. Soc. 1949, 12, 1-34. [CrossRef]

42. Haight, F.A. Traffic safety in developing countries. J. Saf. Res. 1980, 12, 50-58. [CrossRef]

43. Jacobs, G.D.; Cutting, C.A. Further research on accident rates in developing countries. Accid Anal. Prev. 1986, 18, 119-127. [CrossRef]

44. Nicholson, A.J.; Jadaan, K.S. A review of recent developments and current issues in road safety. J. Traffic Med. 1989, 17, 13-22.

45. Zwi, A.B.; Forjouh, S.; Murugusamphillay, S. Injuries in developing countries: Policy response needed now. Trans. R. Soc. Trop. Med. Hyg. 1996, 90, 593-595. [PubMed]

46. Murray, C.J.L.; Lopez, A.D. Mortality by cause for eight regions of the World: Global burden of disease Study. Lancet 1997, 349, 1269-1276. [CrossRef]

47. Bener, A.; Abu-Zidan, F.M.; Bensiali, A.K.; Al-Mulla, A.A.; Jadaan, K.S. Strategy to improve road safety in developing countries. Saudi Med. J. 2003, 24, 603-608. [PubMed]

48. Belin, M.-Å.; Tillgren, P.; Vedung, E. Vision Zero-A road safety policy innovation. Int. J. Inj. Control Saf. Promot. 2012, 19, 171-179. [CrossRef]

49. Haagsma, J.A.; Graetz, N.; Bolliger, I.; Naghavi, M.; Higashi, H.; Mullany, E.C.; Abera, S.F.; Abraham, J.P.; Adofo, K.; Alsharif, U.; et al. The global burden of injury: Incidence, mortality, disability-adjusted life years and time trends from the Global Burden of Disease study 2013. Inj. Prev. 2016, 22, 3-18. [PubMed]

50. Goniewicz, K.; Goniewicz, M.; Pawłowski, W.; Fiedor, P. Road accident rates: Strategies and programmes for improving road traffic safety. Eur. J. Trauma Emerg. Surg. 2016, 42, 433-438. [CrossRef]

51. Beck, B.; Cameron, P.A.; Fitzgerald, M.C.; Judson, R.T.; Teague, W.; Lyons, R.A.; Gabbe, B.J. Road safety: Serious injuries remain a major unsolved problem. Med. J. Aust. 2017, 207, 244-249. [CrossRef] [PubMed]

52. WHO. Available online: https://www.who.int/ (accessed on 13 August 2021).

53. Website of the International Traffic Safety Data and Analysis Group (IRTAD). Available online: https://www.itf-oecd.org/IRTAD (accessed on 14 August 2021).

54. Elvik, R.; Goel, R. Safety-in-numbers: An updated meta-analysis of estimates. Accid. Anal. Prev. 2019, 129, 136-147. [CrossRef] 
55. WHO. Global Status Report on Road Safety, Geneva. 2015. Available online: http://www.who.int/violence_injury_prevention/ road_traffic/en/ (accessed on 15 August 2021).

56. Blinkin, M.Y.; Reshetova, E.M. Road Safety: The History of the Issue, International Experience, Basic Institutions; Publishing House of the Higher School of Economics: Moscow, Russia, 2013; 240p. (In Russian)

57. Wijnen, W.; Weijermars, W.; Schoeters, A.; van den Berghe, W.; Bauer, R.; Carnis, L.; Elvik, R.; Martensen, H. An analysis of official road crash cost estimates in European countries. Saf. Sci. 2019, 113, 318-327. [CrossRef]

58. Blincoe, L.J.; Miller, T.R.; Zaloshnja, E.; Lawrence, B.A. The Economic and Societal Impact of Motor Vehicle Crashes, 2010; (Revised) (Report No. DOT HS 812 013); National Highway Traffic Safety Administration: Washington, DC, USA, 2015.

59. Kato, S.; Takeuchi, E.; Ishiguro, Y.; Ninomiya, Y.; Takeda, K.; Hamada, T. An Open Approach to Autonomous Vehicles. IEEE Micro 2015, 35, 60-68. [CrossRef]

60. Fagnant, D.J.; Kockelman, K. Preparing a nation for autonomous vehicles: Opportunities, barriers and policy recommendations. Transp. Res. Part A Policy Pract. 2015, 77, 167-181. [CrossRef]

61. Bonnefon, J.-F.; Shariff, A.; Rahwan, I.Y. The social dilemma of autonomous vehicles. Science 2016, 352, 1573-1576. [CrossRef]

62. Faisal, A.; Kamruzzaman, M.; Yigitcanlar, T.; Currie, G. Understanding autonomous vehicles: A systematic literature review on capability, impact, planning and policy. J. Transp. Land Use 2019, 12, 45-72. [CrossRef]

63. Hulse, L.M.; Xie, H.; Galea, E.R. Perceptions of autonomous vehicles: Relationships with road users, risk, gender and age. Saf. Sci. 2018, 102, 1-13. [CrossRef]

64. Khadaroo, J.; \& Seetanah, B. The Role of Transport Infrastructure in International Tourism Development: A Gravity Model Approach. Tour. Manag. 2008, 29, 831-840. [CrossRef]

65. Kolik, A.; Radziwill, A.; Turdyeva, N. Improving Transport Infrastructure in Russia. In OECD Economics Department Working Papers; No. 1193; OECD Publishing: Paris, France, 2015. [CrossRef]

66. Qin, Y. China's Transport Infrastructure Investment: Past, Present, and Future. Asian Econ. Policy Rev. 2016, 11, 199-217. [CrossRef]

67. Hamed, M.M. Analysis of pedestrians' behavior at pedestrian crossings. Saf. Sci. 2001, 38, 63-82. [CrossRef]

68. Sucha, M.; Dostal, D.; Risser, R. Pedestrian-driver communication and decision strategies at marked crossings. Accid. Anal. Prev. 2017, 102, 41-50. [CrossRef]

69. Van den Elshout, S.; Molenaar, R.; Wester, B. Adaptive traffic management in cities-Comparing decision-making methods. Sci. Total Environ. 2014, 488-489, 382-388. [CrossRef]

70. Wouters, P.I.J.; Bos, J.M.J. Traffic accident reduction by monitoring driver behaviour with in-car data recorders. Accid. Anal. Prev. 2000, 32, 643-650. [CrossRef]

71. Warner, H.W.; Åberg, L. Drivers' decision to speed: A study inspired by the theory of planned behavior. Transp. Res. Part F Traffic Psychol. Behav. 2006, 9, 427-433. [CrossRef]

72. Taubman-Ben-Ari, O.; Mikulincer, M.; Gillath, O. The multidimensional driving style inventory-Scale construct and validation Accid. Anal. Prev. 2004, 36, 323-332. [CrossRef]

73. Burger, J.M.; Cooper, H.M. The desirability of control. Motiv. Emot. 1979, 3, 381-393. [CrossRef]

74. Zuckerman, M.; Kuhlman, D.M.; Joireman, M.; Kraft, H. Five robust questionnaire scale factors of personality without culture. Personal. Individ. Differ. 1993, 12, 929-941. [CrossRef]

75. Poó, F.; Taubman-Ben-Ari, O.; Ledesma, R.; Díaz-Lázaro, C. Reliability and validity of a Spanish-language version of the multidimensional driving style inventory. Transp. Res. Part F Traffic Psychol. Behav. 2013, 17, 75-87. [CrossRef]

76. Holman, A.; Havârneanu, C. The Romanian version of the multidimensional driving style inventory: Psychometric properties and cultural specificities. Transp. Res. Part F Traffic Psychol. Behav. 2015, 35, 45-59. [CrossRef]

77. Totkova, Z.; Racheva, R. The Bulgarian Version of the Multidimensional Driving Style Inventory: Psychometric Properties. Behav. Sci. 2019, 9, 145. [CrossRef]

78. Evans, L. Risks older drivers face themselves and threats they pose to other road users. Int. J. Epidemiol. 2000, $29,315-322$. [CrossRef]

79. Bernhoft, I.M.; \& Carstensen, G. Preferences and behaviour of pedestrians and cyclists by age and gender. Transp. Res. Part F Traffic Psychol. Behav. 2008, 11, 83-95. [CrossRef]

80. Gonawala, R.J.; Badami, N.B.; Electicwala, F.; Kumar, R. Impact of Elderly Road Users Characteristics at Intersection. Procedia Soc. Behav. Sci. 2013, 104, 1088-1094. [CrossRef]

81. Zaidel, D.M. A modeling perspective on the culture of driving. Accid. Anal. Prev. 1992, 24, 585-597. [CrossRef]

82. Guldenmund, F.W. The nature of safety culture: A review of theory and research. Saf. Sci. 2000, 34, $215-257$.

83. Zhang, W.; Huang, Y.; Roetting, M.; Wang, Y.; Wei, H. Driver's views and behaviours about safety in China: What do they not know about driving? Accid. Anal. Prev. 2006, 38, 22-27. [PubMed]

84. Özkan, T.; Lajunen, T. Person and Environment. In Handbook of Traffic Psychology; Porter, B.E., Waltham, M.A., Eds.; Academic Press: London, UK, 2011; pp. 179-192. [CrossRef]

85. Gaygisiz, E. Cultural values and governance quality as correlates of road traffic fatalities: A nation level analysis. Accid. Anal. Prev. 2010, 42, 1894-1901.

86. Horne, J.A.; Reyner, L.A. Sleep related vehicle accidents. BMJ 1995, 310, 565-567. [PubMed]

87. Strohl, K.P. Sleep apnea, sleepiness, and driving risk. Am. J. Respir. Crit. Care Med. 1994, 150, 1463. 
88. Bell, M.G.H. Policy issues for the future intelligent road transport infrastructure. IEE Proc. Intell. Transp. Syst. 2006, $153,147$. [CrossRef]

89. Losurdo, F.; Dileo, I.; Siergiejczyk, M.; Krzykowska, K.; Krzykowski, M. Innovation in the ICT Infrastructure as a Key Factor in Enhancing Road Safety: A Multi-sectoral Approach. In Proceedings of the 2017 25th International Conference on Systems Engineering (ICSEng), Las Vegas, NV, USA, 22-24 August 2017; pp. 157-162. [CrossRef]

90. Hegyi, P.; Borsos, A.; Koren, C. Searching possible accident black spot locations with accident analysis and gis software based on GPS coordinates. Pollack Period 2017, 12, 129-140. [CrossRef]

91. Dereli, M.A.; Erdogan, S. A new model for determining the traffic accident black spots using GIS-aided spatial statistical methods. Transp. Res. Part A Policy Pract. 2017, 103, 106-117.

92. Al-Jameel, H.A.; AbdAbas, A.Y. Identifying black spot locations at karbala city by using GIS system. Int. J. Civ. Eng. 2018, 9, 933-938.

93. Shen, L.; Lu, J.; Long, M.; Chen, T. Identification of accident blackspots on rural roads using grid clustering and principal component clustering. Math. Probl. Eng. 2019, 2019, 2151284. [CrossRef]

94. Bisht, L.S.; Tiwari, G. Assessing the Black Spots Focused Policies for Indian National Highways. Transp. Res. Procedia 2019, 48, 2537-2549. [CrossRef]

95. Vindhya Shree, M.P.; Shashikiran, C.R.; Nandish Shanabog, C.S. Prioritization of Accident Black Spots using GIS. Int. J. Eng. Res. 2020, 9, 653-666. [CrossRef]

96. Yuan, T.; Zeng, X.; Shi, T. Identifying Urban road black spots with a novel method based on the firefly clustering algorithm and a geographic information system. Sustainability 2020, 12, 2091. [CrossRef]

97. Chen, Y.; Wang, K.; Zhang, Y.; Shi, Q. Identification of black spots on highways using fault tree analysis and vehicle safety boundaries. J. Transp. Saf. Secur. 2021, 13, 46-68. [CrossRef]

98. Almoshaogeh, M.; Abdulrehman, R.; Haider, H.; Alharbi, F.; Jamal, A.; Alarifi, S.; Shafiquzzaman, M. Traffic Accident Risk Assessment Framework for Qassim, Saudi Arabia: Evaluating the Impact of Speed Cameras. Appl. Sci. 2021, 11, 6682. [CrossRef]

99. European Accident Research and Safety Report. 2017. Available online: https://ec.europa.eu/transport/road_safety/sites/ roadsafety/files/pdf/statistics/dacota/asr2017.pdf (accessed on 18 August 2021).

100. European Accident Research and Safety Report. 2018. Available online: https://ec.europa.eu/transport/road_safety/sites/ roadsafety / files/pdf/statistics/dacota/asr2018.pdf (accessed on 18 August 2021).

101. Thiffault, P.; Bergeron, J. Monotony of road environment and driver fatigue: A simulator study. Accid. Anal. Prev. 2003, 35, 381-391. [CrossRef]

102. Saneinejad, S.; Roorda, M.J.; Kennedy, C. Modelling the impact of weather conditions on active transportation travel behaviour. Transp. Res. Part D Transp. Environ. 2012, 17, 129-137. [CrossRef]

103. Chu, W.; Wu, C.; Atombo, C.; Zhang, H.; Özkan, T. Traffic climate, driver behaviour, and accidents involvement in China. Accid. Anal. Prev. 2019, 122, 119-126. [CrossRef]

104. Horowitz, R.; Varaiya, P. Control design of an automated highway system. Proc. IEEE 2000, 88, 913-925. [CrossRef]

105. Giannopoulos, G. The application of information and communication technologies in transport. Eur. J. Oper. Res. 2004, 152, 302-320. [CrossRef]

106. Hamdi, S.; Faiedh, H.; Souani, C.; Besbes, K. Road signs classification by ANN for real-time implementation. In Proceedings of the 2017 International Conference on Control, Automation and Diagnosis (ICCAD), Hammamet, Tunisia, 19-21 January 2017; pp. 328-332. [CrossRef]

107. Michon, J.A. A Critical View of Driver Behavior Models: What Do We Know, What Should We Do? In Human Behavior and Traffic Safety; Evans, L., Schwing, R.C., Eds.; Springer: Boston, MA, USA, 1985.

108. Dingil, A.E.; Esztergár-Kiss, D. The Influence of the Covid-19 Pandemic on Mobility Patterns: The First Wave's Results. Transp. Lett. 2021, 13, 434-446. [CrossRef]

109. Cho, S.-H.; Park, H.-C. Exploring the Behaviour Change of Crowding Impedance on Public Transit due to COVID-19 Pandemic: Before and After Comparison. Transp. Lett. 2021, 13, 367-374. [CrossRef]

110. Velmurugan, S.; Mukti, A.; Padma, S. Impacts of COVID-19 on the Transport Sector and Measures as Well as Recommendations of Policies and Future Research: Report on India. 27 September 2020. [CrossRef]

111. Catchpole, J.; Naznin, F. Impact of COVID-19 on Road Crashes in Australia. Available online: https:/ /www.arrb.com.au/latestresearch/report-reveals-facts-about-covid-19-lockdown-road-crashes (accessed on 16 August 2021).

112. Katrakazas, C.; Michelaraki, E.; Sekadakis, M.; Yannis, G. A descriptive analysis of the effect of the COVID-19 pandemic on driving behavior and road safety. Transp. Res. Interdiscip. Perspect. 2020, 7, 100186. [CrossRef]

113. Budd, L.; Ison, S. Responsible transport: A post-COVID agenda for transport policy and practice. Transp. Res. Interdiscip. Perspect. 2020, 6, 100151. [CrossRef]

114. Kolesov, V.I. Dynamic characteristics of the innovation process based on the generalized golden section. In Innovations in the Management of Regional and Sectoral Development; TIU: Tyumen, Russia, 2019; pp. 121-127. (In Russian)

115. Soroko, E.M. Structural Harmony of Systems; Science and Technology: Minsk, Belarus, 1984; 264p. (In Russian)

116. Soroko, E.M. The Criterion of Harmony of Self-Organizing Socio-Natural Systems; Scientific Report; Institute of the Noosphere of the Far Eastern Branch of the USSR Academy of Sciences: Vladivostok, Russia, 1989; 83p. (In Russian) 
117. Kolesov, V.I. Criterion of system harmony. In New Information Technologies in the Oil and Gas Industry and Education; TIU: Tyumen, Russia, 2019; pp. 206-212. (In Russian)

118. Shastova, G.A. Choice and Optimization of the Structure of Information Systems; Energia: Moscow, Russia, 1972; 256p. (In Russian)

119. Prangishvili, I.V. Problems of effective management of complex socio-economic and organizational systems. Prop. Relat. Russ. Fed. 2006, 11, 82-86. (In Russian)

120. Ivanus, A.I. Fundamentals of Harmonious Management (the Concept of F-Technology); V.A. Trapeznikov's Institute of Management Problems, RAS: Moscow, Russia, 2004; 82p. (In Russian)

121. Kornai, Y. System paradigm. Soc. Econ. 1999, 3-4, 85-96. (In Russian)

122. Stepin, V.S. Self-developing systems and post-non-classical rationality. Quest. Philos. 2003, 8, 5-17. (In Russian)

123. Kleiner, G.B. System paradigm and system management. Russ. J. Manag. 2008, 6, 27-50. (In Russian)

124. Kolesov, V.I. Reference systems in the metric of the generalized golden s-section. In New Information Technologies in the Oil and Gas Industry and Education; TIU: Tyumen, Russia, 2020; pp. 11-17. (In Russian)

125. Popov, S.A. The Concept of Actual Strategic Management for Modern Russian Companies; Yurayt Publishing House: Moscow, Russia, 2020; 223p. (In Russian)

126. Drucker, P.F. The theory of business. Harv. Bus. Rev. 1994, 72, 95-104.

127. Krutov, V.I.; Glushko, I.M.; Popov, V.V. Fundamentals of Scientific Research; Higher School: Moscow, Russia, 1989; 400p. (In Russian) 